ROBERT FLOOD

International Monetary Fund

NANCY MARION

Dartmouth College

\title{
Holding International Reserves in an Era of High Capital Mobility
}

\section{L} ast September, as calls grew louder for European Central Bank (ECB) intervention to reverse the euro's fall, the lead of an Economist article asked, "If central banks are so reluctant to intervene in foreign-exchange markets, why do they still hold so many reserves?' The article went on to say that at the time, the ECB and the euro area's national central banks together held about $\$ 226$ billion of foreign-exchange reserves, not counting their sizable gold holdings. ${ }^{1}$

The question is being asked more often these days. The Economist suggested that the idea of having an abundance of reserves is partly a carryover from the Bretton Woods system, when central banks were obligated to defend their parities against the dollar through intervention and so needed a lot of reserves. Yet, as the Economist noted, Bretton Woods broke down thirty years ago, and today many fewer countries peg their exchange rates. Indeed the currency and financial crises of the 1990s have led some observers to conclude that in a world of high capital mobility, fixed exchange rates such as the European exchange-rate mechanism or the East Asian pegs before 1997-98 cannot work for long. ${ }^{2}$ As a result, more countries have shifted to floating exchange rates. With less need to hold reserves to defend currency values, one would expect global reserve holdings to decline. But just the opposite has occurredworld reserve holdings are at record levels.

Figure 1 shows that global reserve holdings (excluding gold) were equivalent to seventeen weeks of imports at the end of 1999, almost double what

The authors thank Stefan Hubrich for his outstanding research assistance and substantive research suggestions.

1. Economist, September 23-29, 2000, p. 89.

2. See, for example, Fischer (2001). 
Figure 1. Global Reserves Excluding Gold-1960-99

Number of weeks' import cover

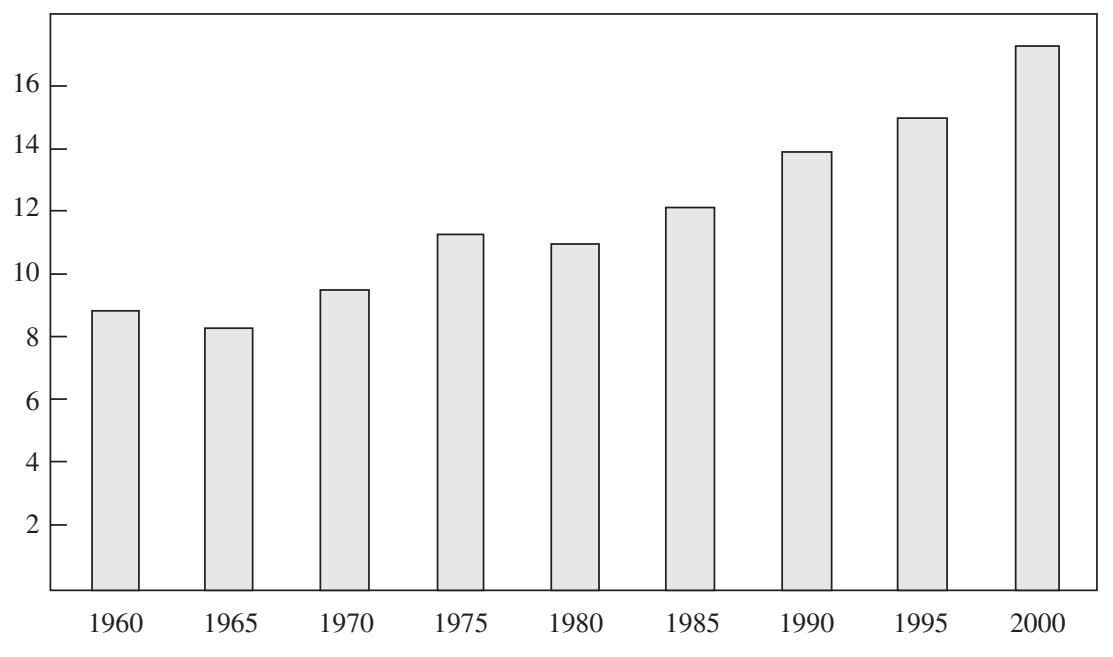

Source: Authors' calculations using data from the IMF's International Financial Statistics. Details can be found in appendix B.

they were at the end of 1960 and about 20 percent higher than at the start of the 1990s. When measured as a share of global income, reserve holdings have also trended upward, as shown in figure 2. At the end of 1999, reserves were about 6 percent of global gross domestic product (GDP), 3.5 times what they were at the end of 1960 and 50 percent higher than in $1990 .^{3}$

Calvo and Reinhart believe that reserve holdings are high for some countries because their announced shift to greater exchange-rate flexibility is an illusion. ${ }^{4}$ Examining thirty-nine countries during the January 1970 November 1999 period, Calvo and Reinhart find that self-identified floaters and managed floaters look more like peggers (in terms of the probability that the monthly percentage change in their nominal exchange rate will fall within a narrow band). Thus some countries may hold large stocks of reserves because they still manage their exchange rates. Hausman, Panizza, and Stein suggest that countries unable to borrow internationally in their own currency may seek reduced exchange-rate flexibility in order to limit the damage from currency

3. The countries in the global sample vary over time. Using a sample of forty-four countries for which there are continuous data and which account for 57 percent of global reserve holdings today, the same pattern of increased reserve holdings over time is uncovered. How these trends are modified when measured reserves include gold holdings is discussed later in this paper.

4. Calvo and Reinhart (2000). 
Figure 2. Global Reserves Excluding Gold as a Percentage of World GDPa

Percent

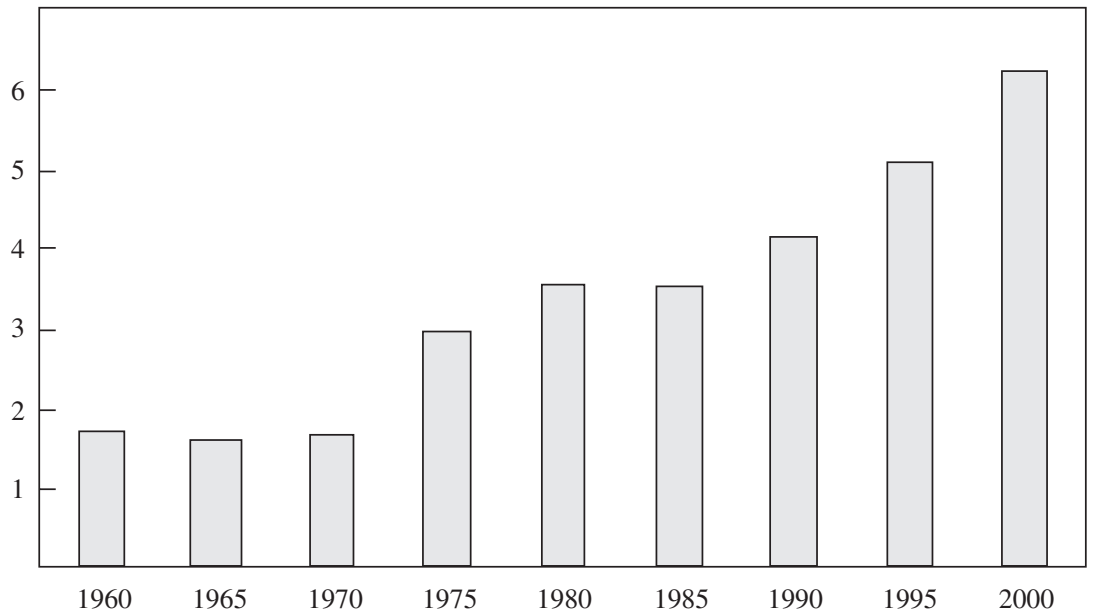

Source: Authors' calculations using data from the IMF's International Financial Statistics and World Economic Outlook. Details can be found in appendix B.

a. World GDP unavailable for 1960s; 1960 and 1965 ratios use sample of countries accounting for over 90 percent of global reserve holdings in 1960s.

mismatches in their liabilities. ${ }^{5}$ That exchange-rate policy requires a potentially large stockpile of reserves.

Countries actually operating floating exchange rates might still hold reserves so they can intervene in the foreign-exchange market on occasion to influence the value of their currencies. But since most studies suggest that interventionat least the sterilized kind that neutralizes the effects of foreign-exchange market intervention on the money supply-rarely works, and since intervention occurs so infrequently in practice, there is still the puzzle of why floaters hold so many reserves. On the surface, holding lots of reserves seems like a costly practice. ${ }^{6}$

In the end the Economist was able to offer only one reason other than exchange-rate management for why a rational central bank might want to hold a large stockpile of reserves. The reason is to have "a safety cushion in times

5. Hausman, Panizza, and Stein (2000).

6. "It is rather as though a household with lots of cash sitting idle in a low-interest bank account was at the same time paying a much higher interest rate on its debts. It would make more sense to repay some of that debt." (Economist, September 23-29, 2000, p. 90.) See also Flood and Jeanne (2000). However, once the capital gains on foreign-currency reserves arising from exchange-rate changes are taken into account, the opportunity cost of holding reserves is negligible. 
of war, a trade embargo, or a banking crisis."7 In most developed countries, the need for such a large safety net seems unjustified, especially if they can borrow foreign currency in the world capital market when needed. For other countries, however, holding large reserves as a safety cushion may be understandable.

It may make sense, for example, for Taiwan to hold large reserves because it is worried about the risk of conflict with China. ${ }^{8}$ Moreover, it cannot obtain emergency funds from the International Monetary Fund (IMF) because it is not an IMF member country. Indeed, Taiwan currently holds the world's fourth-largest stock of international reserves (excluding gold), about $\$ 110$ billion at the end of February 2001. Only Japan, China, and Hong Kong hold more, with reserves of $\$ 357$ billion, $\$ 178$ billion, and $\$ 114$ billion, respectively. ${ }^{9}$

South Korea, also facing a hostile power on its northern border, ranks just below Taiwan in reserve holdings. The country increased its reserves fifteenfold in the last three years, from a low of $\$ 6$ billion in "usable" reserves in December 1997, to $\$ 95$ billion in foreign-exchange reserves (excluding gold) by the end of February 2001. ${ }^{10}$ But Korea's large increase in reserves may also be the result of additional factors. It may be a by-product of heavily managing its exchange rate to keep it from rising in the face of current-account surpluses and renewed capital inflows. It may also be a response to its recent financial crisis, reflecting a determination to have "sufficient" liquidity to cope with any future crisis.

Obviously, there could be any number of reasons why central banks continue to hold substantial quantities of reserves. It is necessary to take a systematic look at the issue. This is not the first time that researchers have turned their attention to the subject of central bank reserve holdings. In the mid-1960s the debate about needed reforms of the Bretton Woods system led researchers to ask whether reserve levels were "adequate" and were distributed optimally across countries. In the late 1970s and early 1980s, researchers were interested in whether the "demand for reserves" had substantially changed after the demise of Bretton Woods. They were also curious about whether developed and developing countries differed in their "demand for reserves." Eventually attention was directed away from reserve holdings by the widespread assumption that international reserves would be stable - and probably

7. Economist, September 23-29, 2000, p. 90.

8. Economist, September 23-29, 2000.

9. IMF, International Financial Statistics, and Central Bank of China.

10. Bank of Korea and IMF, International Financial Statistics. 
low-in an era of increased exchange-rate flexibility and very high capital mobility.

Now is a good time to revisit this issue. The last decade of the twentieth century has strengthened three trends in the international economy that could potentially have an important influence on reserve holdings. The first is increasing capital mobility, as more economies liberalize their financial markets and dismantle capital controls. The second is the increasing frequency and intensity of currency and financial crises, with a number of countries facing speculative attacks on their fixed exchange rates or panicked foreign creditors worried about possible defaults. The third trend is the increasing number of countries reporting a switch to flexible exchange rates. How have these trends affected central bank reserve holdings? Are the determinants of international reserve holdings in a world of high capital mobility different from the earlier era?

This paper examines some stylized facts about global and country-specific reserve holdings and discusses the buffer stock model of reserve holdings introduced by Frenkel and Jovanovic. ${ }^{11}$ The model says that central banks choose an optimal level of reserves to balance the macroeconomic adjustment costs incurred in the absence of reserves with the opportunity cost of holding reserves. Reserve holdings turn out to be a stable function of just a few variables - the adjustment cost, the opportunity cost, and reserve volatility. We study the empirical application of the buffer stock (inventory) model when we attempt to replicate it and then extend it using more recent data.

We argue that earlier methods for taking the buffer stock model to data are possibly misguided, and propose a different empirical approach for testing the buffer stock model that is consistent with the current experience of high capital mobility and periodic currency crises. It is also consistent with the view that reserve movements are an endogenous response to central bank and private sector behavior. This paper provides a new measure of the volatility that affects the central bank decision to hold reserves, a measure that captures the increasingly important phenomenon of nominal (financial) uncertainty.

We test the buffer stock model of optimal reserve holdings using our new measure of volatility and also make use of market-determined interest rates that have appeared in the aftermath of financial liberalizations to construct a measure of the opportunity cost of holding reserves. We also consider some factors not identified specifically by the buffer stock model that might affect 
adjustment costs, such as the country's degree of exchange-rate flexibility and its financial and real-side openness.

Our empirical work shows that the performance of the buffer stock model in explaining reserve holdings in the 1990s is mixed. The buffer stock model's prediction that international reserve holdings increase with higher volatility is quite robust. That said, most of the variation in reserve holdings is explained by country-specific adjustment costs (fixed effects) that have, to date, not been made explicit. The remaining challenge is to explain these cross-country variations in reserve holdings.

\section{A Descriptive Look at Reserve Holdings}

Before taking a look at international reserve holding patterns over time, both globally and for specific country groups, some measurement issues need to be addressed.

The first measurement issue concerns the definition of reserves. In an oftcited article, Robert Heller wrote that international reserves must possess two qualities. ${ }^{12}$ First, "they must be acceptable at all times to foreign economic units for payment of financial obligations." Second, "their value, expressed in foreign units of account, should be known with certainty." ${ }^{13}$ Using Heller's definition, the four types of assets that qualify are official holdings of gold, special drawing rights (SDRs), convertible foreign exchange, and the unconditional drawing rights with the IMF (the country's reserve position in the Fund). ${ }^{14}$

Some economists in the 1960s puzzled over the merits of adjusting this measure of reserve assets to account for public and private liabilities toward foreigners. ${ }^{15}$ They concluded that there were no acceptable criteria for including or excluding the many types of these liabilities. For practical reasons, then, almost all studies thereafter concentrated on gross foreign reserve assets.

12. Robert Heller (1966).

13. Heller (1966, pp. 296-97).

14. The reserve position in the Fund comprises the reserve tranche position and has the characteristics of a reserve asset. Technically, the reserve tranche position "arises from the payment of part of a member's subscription in reserve assets and the Fund's net use of the member's currency. Normally, a member's reserve tranche position is equal to its quota less the adjusted Fund holdings of its currency, less subscriptions receivable, less the balances held in the administrative accounts of the Fund." (IMF, International Financial Statistics, June 2001, p. 14, and other issues.)

15. See, for example, Kenen and Yudin (1965). 
Even though gold holdings were a significant share of monetary authorities' reserve assets under the Bretton Woods system, they have declined in relative importance since then. ${ }^{16}$ Probably for that reason, most empirical studies assessing the determinants of financial crises in the 1980s and 1990s have used a reserves measure that excludes gold. Yet if patterns of reserve holdings over the last fifty years are to be examined, it is important that gold be included. Even though official gold holdings accounted for less than 3 percent of international reserve holdings at the end of 1999, in 1960 they composed about two-thirds of reserve holdings. ${ }^{17}$

With gold included in the reserves measure, one must decide how to value it. Under the Bretton Woods system, official gold holdings were valued at $\$ 35$ an ounce. Eventually the SDR replaced the U.S. dollar as the conversion rate. We follow current IMF convention and value official gold holdings at SDR 35 per ounce. ${ }^{18}$

In our examination of data, we define the monetary authority's international reserve holdings in the standard way-as the sum of gold (valued at SDR 35 per ounce), SDRs, foreign exchange, and reserve position in the fund. We denominate them in end-of-period billions of U.S. dollars.

Finally, individual countries' reserve holdings cannot be compared or traced through time unless they are scaled in some way to reflect differences in countries' size. One possibility is to scale reserves by gross national product (GNP), and we do so in a number of the time-series comparisons below. In our later empirical work we investigate several scaling methods.

It is worth noting, however, that in the early postwar period the most widely used scale variable was imports. The reserves-to-imports ratio was thought to be targeted by countries as part of their reserve-management policies. The rationale for this scaling variable was never fully justified. Grubel, in his survey of the early reserves literature, suggested that the choice was influenced by the quantity theory of money. ${ }^{19}$ Since private persons and governments required cash to even out receipts and payments, and in the case of the private sector the volume of receipts and payments was measured by national income, the analogous measure for governments was thought to be imports. Though

16. The Second Amendment to the Articles of Agreement of the International Monetary Fund, which came into effect in 1978, eliminated the special role of gold.

17. IMF, International Financial Statistics.

18. For an alternative way of valuing gold using the London average second fixing rate, see Bussiere and Mulder (1999).

19. Grubel (1971). 
Figure 3. Global Reserves Including Gold-1960-99

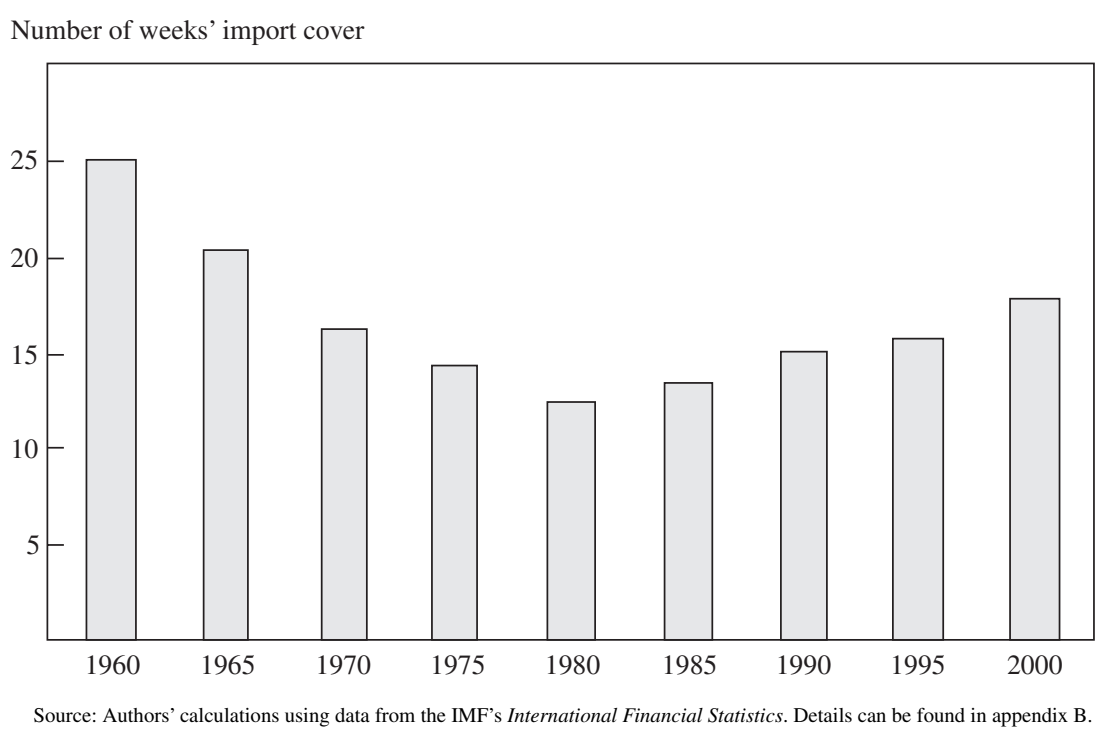

the analogy was imperfect, even at the time, the reserves-to-imports ratio is still used today in popular discussions of reserve "adequacy."

The notion of "reserve adequacy" changed with the onset of the 1990s' currency and financial crises. ${ }^{20}$ Calvo suggested that a country's vulnerability to crisis should be measured, in part, by the size of its money supply, defined broadly, relative to its reserve holdings, since broad money reflects a country's potential exposure to the withdrawal of assets. ${ }^{21}$ In that case broad money, or M2, would be an appropriate scaling variable. Empirical crisis-prediction models have shown that the ratio of short-term foreign-currency debt in relation to reserves was an important determinant of a country's vulnerability to financial crisis in the 1990s. ${ }^{22}$ That would suggest reserves scaled by shortterm foreign-currency debt should be an important variable to monitor over time. The idea of scaling reserves by some foreign liability measure brings us full circle to the debates in the 1960s about whether to report reserves in gross terms or in net terms that are free of claims on them.

Global international reserves (excluding gold) have been increasing since 1960 , whether they are measured in terms of weeks of import cover or as a

20. The post-1980 speculative attack literature has emphasized the point that "reserve adequacy" is different for different policy packages. See, for example, Flood and Marion (1999).

21. Calvo (1996).

22. See, for example, Radelet and Sachs (1998). 
Figure 4. Global Reserves Including Gold as a Percentage of World GDPa_1960-99

Percent

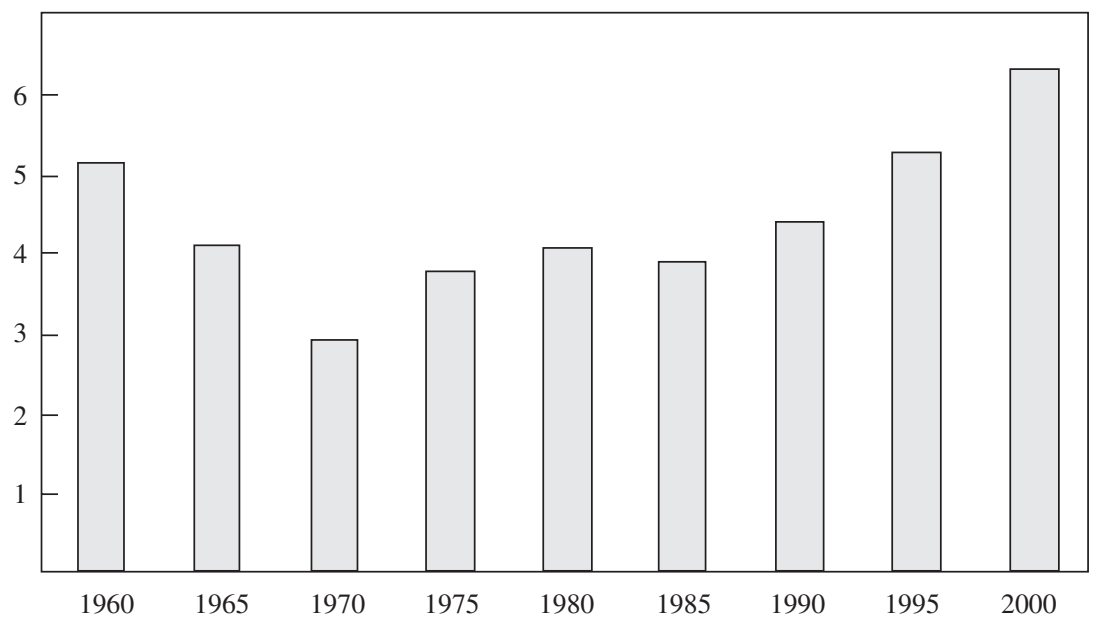

Source: Authors' calculations using data from the IMF's International Financial Statistics and World Economic Outlook. Details can be found in appendix B.

a. World GDP unavailable for 1960s; 1960 and 1965 ratios use sample of countries accounting for over 90 percent of global reserve holdings in 1960s.

share of income, as is shown in figures 1 and 2 . We now examine the trend of international reserve holdings over time using a more complete measure of reserves that includes gold holdings.

When gold is included in the reserves measure, global reserve holdings in terms of weeks of import cover or as a share of world GDP exhibit a different pattern, as revealed in figures 3 and 4 . In terms of weeks of import cover (figure 3), international reserve holdings have actually fallen over time. They covered 24.8 weeks of imports at the end of 1960 and only 17.5 weeks of imports at the end of 1999. The decline has not been smooth, however. From their peak in 1960, reserves in terms of weeks of import cover fell by more than half over the next twenty years, reaching their lowest point in 1982, the first year of the international debt crisis. Then they began to climb again. Between 1982 and 1999, reserve holdings in terms of weeks of import cover increased by 54 percent, from 11.4 weeks of import cover at the end of 1982 to 17.5 weeks at the end of 1999 .

Figure 4 shows that reserves were 6.3 percent of global income at the end of 1999, about 1 percent higher than at the end of 1960. As in the previous figure, reserve holdings have exhibited a U-shaped pattern over the past 40 years. 
Figure 5. Reserve Holdings in Forty-Four Countries ${ }^{\mathrm{a}}$

Reserves excluding gold

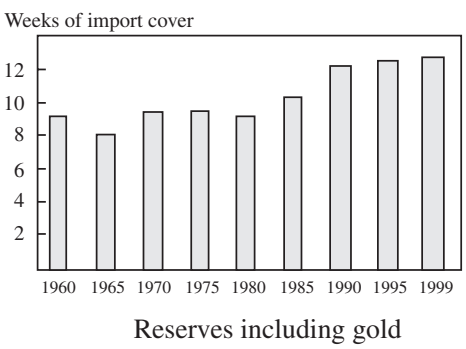

Weeks of import cover

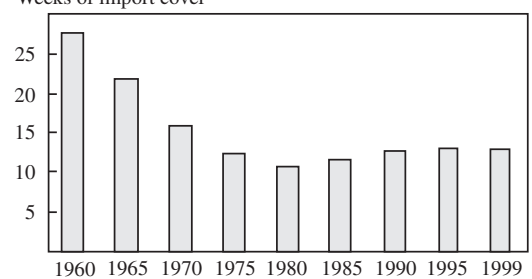

Reserves excluding gold as a percent of GNP

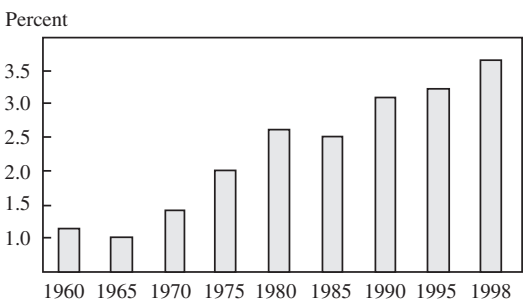

Reserves including gold as a percent of GNP Percent

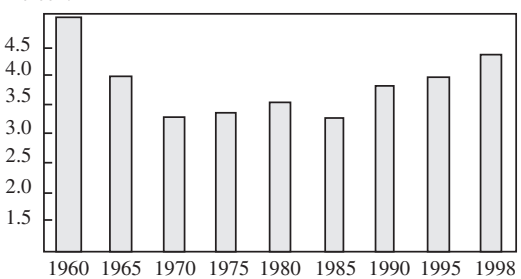

a. Data based on forty-four countries: Australia, Austria, Brazil, Canada, Chile, Costa Rica, Denmark, Dominican Republic, Ecuador, Egypt, El Salvador, Finland, France, Germany, Greece, Guatemala, Honduras, Iceland, India, Ireland, Italy, Jamaica, Japan, Jordan, Korea, Malaysia, Mexico, Netherlands, New Zealand, Norway, Pakistan, Panama, Peru, Philippines, Portugal, South Africa, Spain, Sri Lanka, Sweden, Switzerland, Thailand, the United Kingdom, the United States, and Venezuela.

A problem with the data pictured in figures $1-4$ is that the global totals come from an unbalanced sample. A few countries, such as China, are not included in the early years but are in the sample for the last twenty years. Although scaling probably minimizes the distortions created by an unbalanced sample, we nevertheless want to examine the same data for a balanced sample of countries.

Reserve holdings for forty-four countries between 1960 and 1998 for which we have continuous data are illustrated in figure 5 . These forty-four countries accounted for 57 percent of global reserve holdings at the end of the 1990s. To facilitate comparison with our earlier figures, reserves are measured both excluding and including gold and reserves are scaled both by weeks of import cover and GNP.

The patterns in reserve holdings are the same for the sample of forty-four countries and the global sample. Reserves excluding gold show a marked increase over the last forty years, whether scaled by weeks of import cover or by income. When gold is included in the reserve measure, the decline in reserve holdings after 1960 is eventually reversed. In both the global and 
forty-four-country samples, reserves, including gold, as a share of weeks of import cover are lower now than they were in 1960. As a share of income, they are closer to where they were in 1960.

Data on reserve holdings over time for a number of specific countries are shown in figure 6 . Reserves are measured with gold and scaled by GNP. The time period is more extensive, running from 1948 through 1998. The figures do not reveal any clear pattern across countries. For the developing countries, however, there does seem to be an increase in reserves as a share of national income over the last twenty years. With some notable exceptions, reserve holdings in developed countries have not fallen much over the same interval.

Reserve holdings for a set of fifty-six countries-twenty-two developed and thirty-four developing — over various decades is shown in table 1, which also includes information on a group of emerging markets. In the table, reserves (including gold) are scaled by GNP, imports, and M2. The table confirms the picture that emerges from the earlier figures. Using our more complete measure of reserves, which includes gold, we find that reserve holdings for developed countries, when scaled by GNP, imports, or M2, have not changed appreciably over the last thirty years. In all cases, their reserve holdings are lower in the 1990s than in the Bretton Woods period of 1948-70.

For developing countries reserve holdings have increased over the last three decades, whether scaled by income or imports, but have not changed much when scaled by M2. Compared with the Bretton Woods period, developing countries held more reserves as a share of income or import cover in the 1990s. The growth in reserve holdings over the last two decades has been particularly strong.

The trends for emerging markets are similar to those of developing countries, only more dramatic. Between the 1980s and 1990s, reserve holdings as a share of income have more than doubled. Reserves as a share of both imports and M2 have increased by almost 60 percent.

Reserve patterns for some interesting case studies, namely Taiwan, South Korea, and China, are discussed in appendix A.

\section{Buffer Stock Model}

The buffer stock, or inventory, model has been remarkably successful in explaining international reserve holdings in the post-World War II period. The model postulates that the reserve authority will choose an initial level of 
Figure 6. Reserves/GNP in Individual Countries
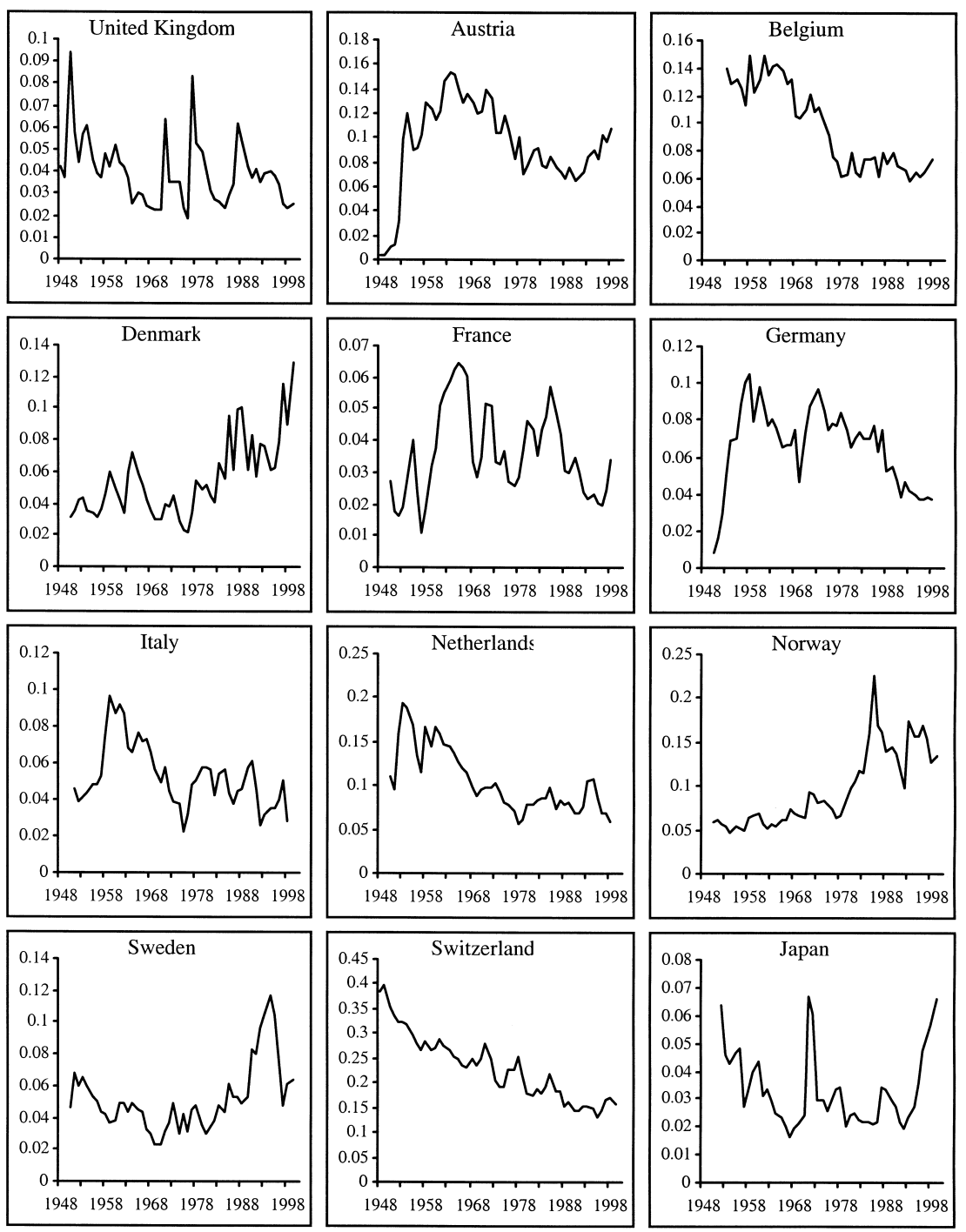
Figure 6. Continued
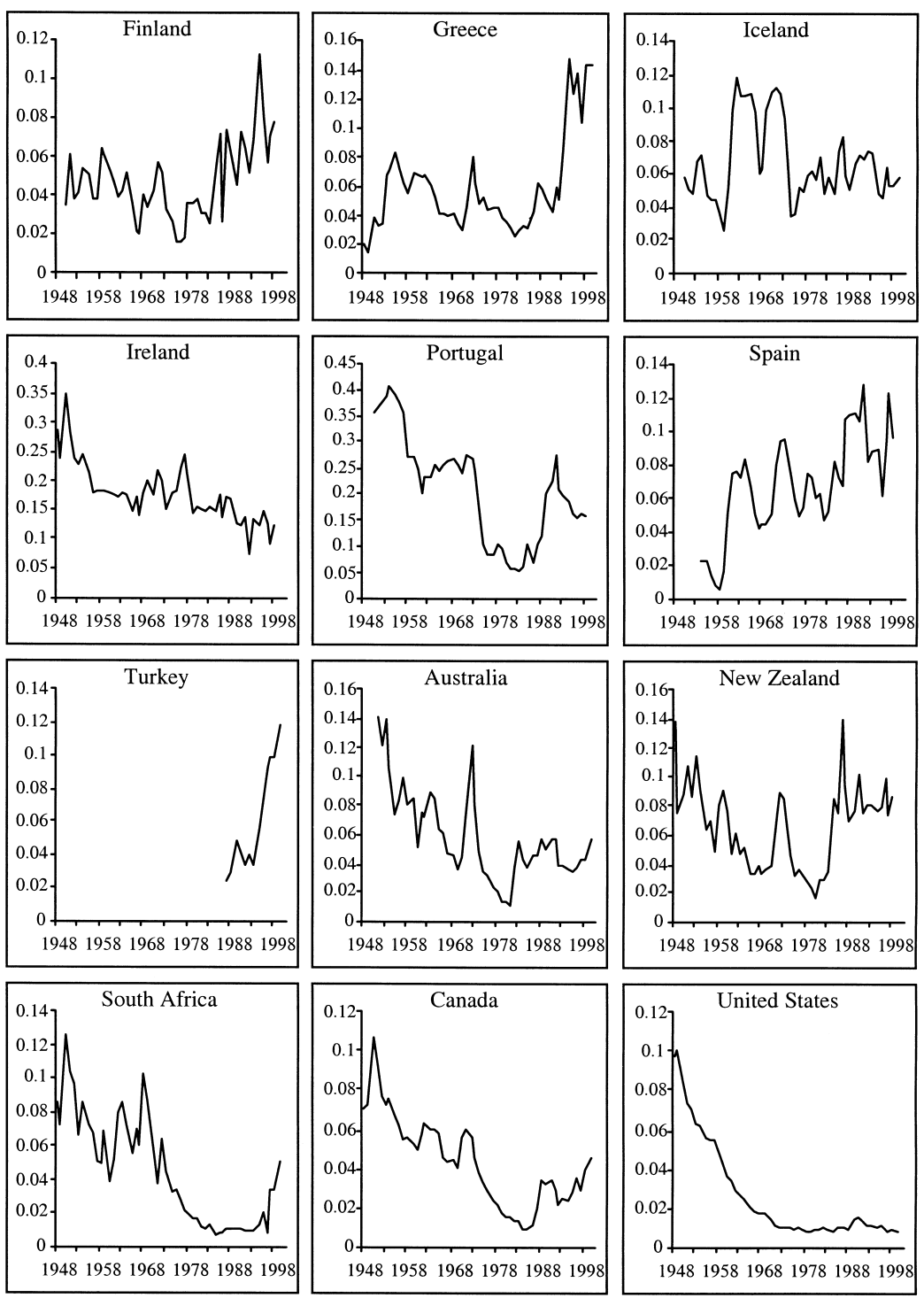
Figure 6. Continued
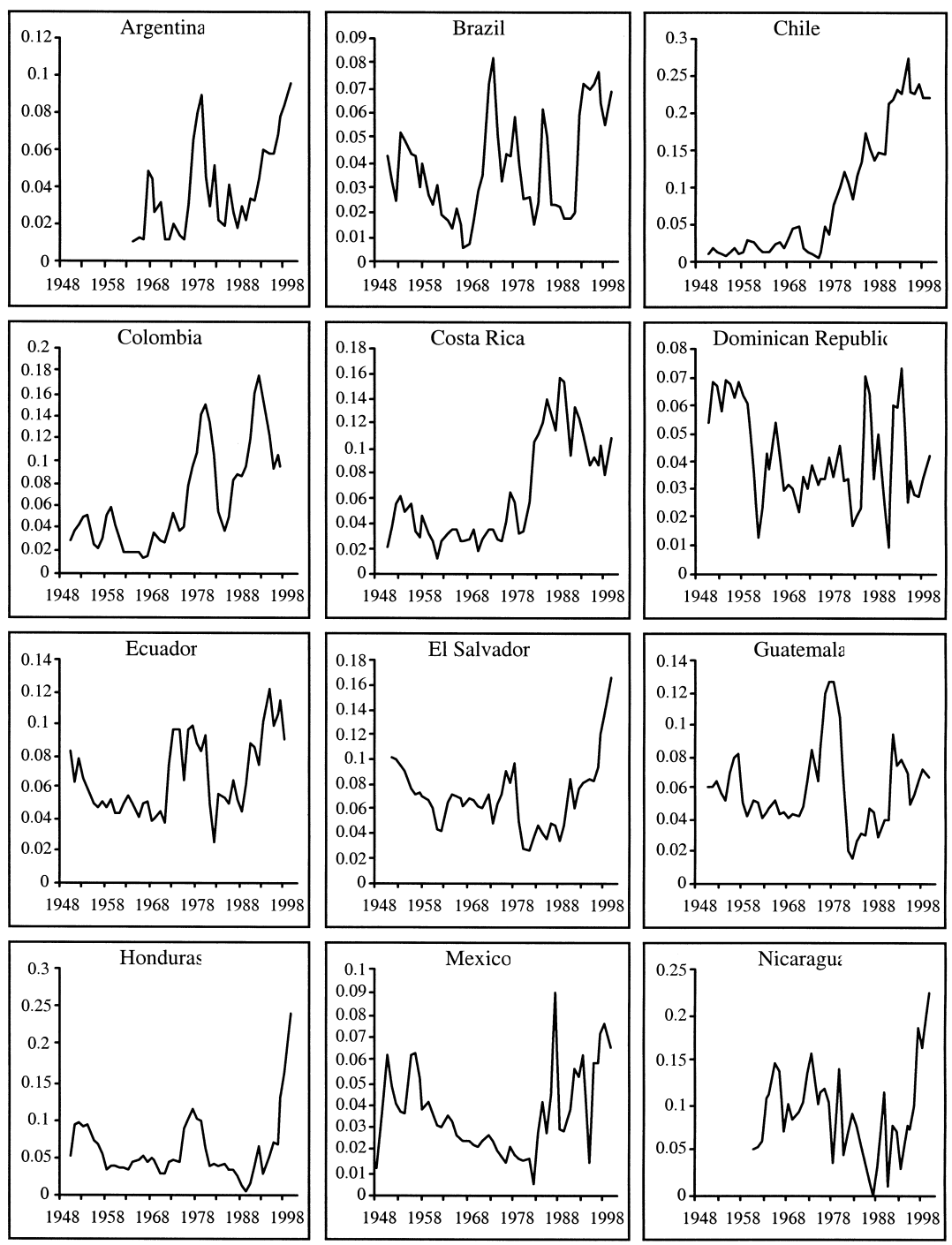
Figure 6. Continued
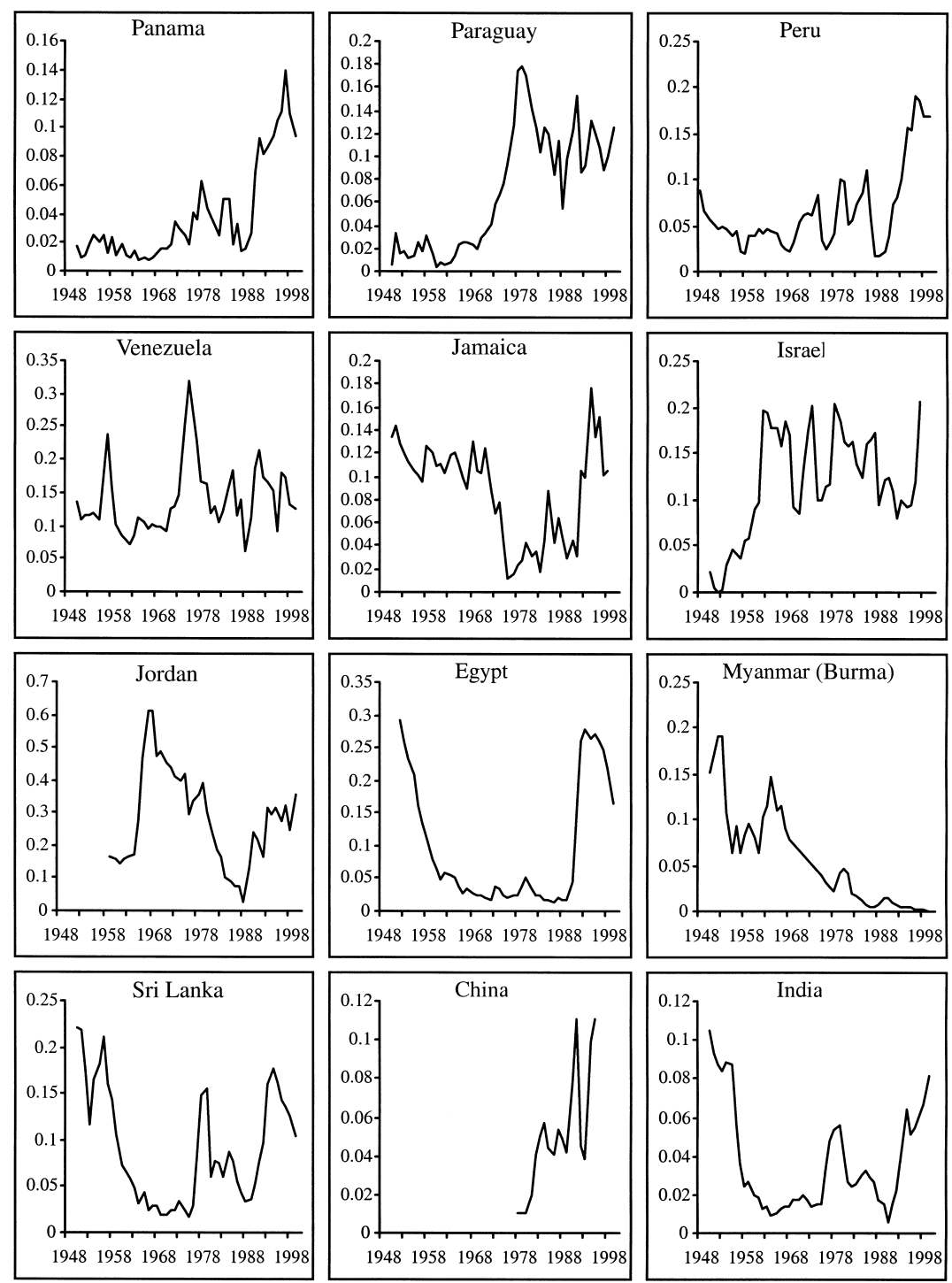
Figure 6. Continued
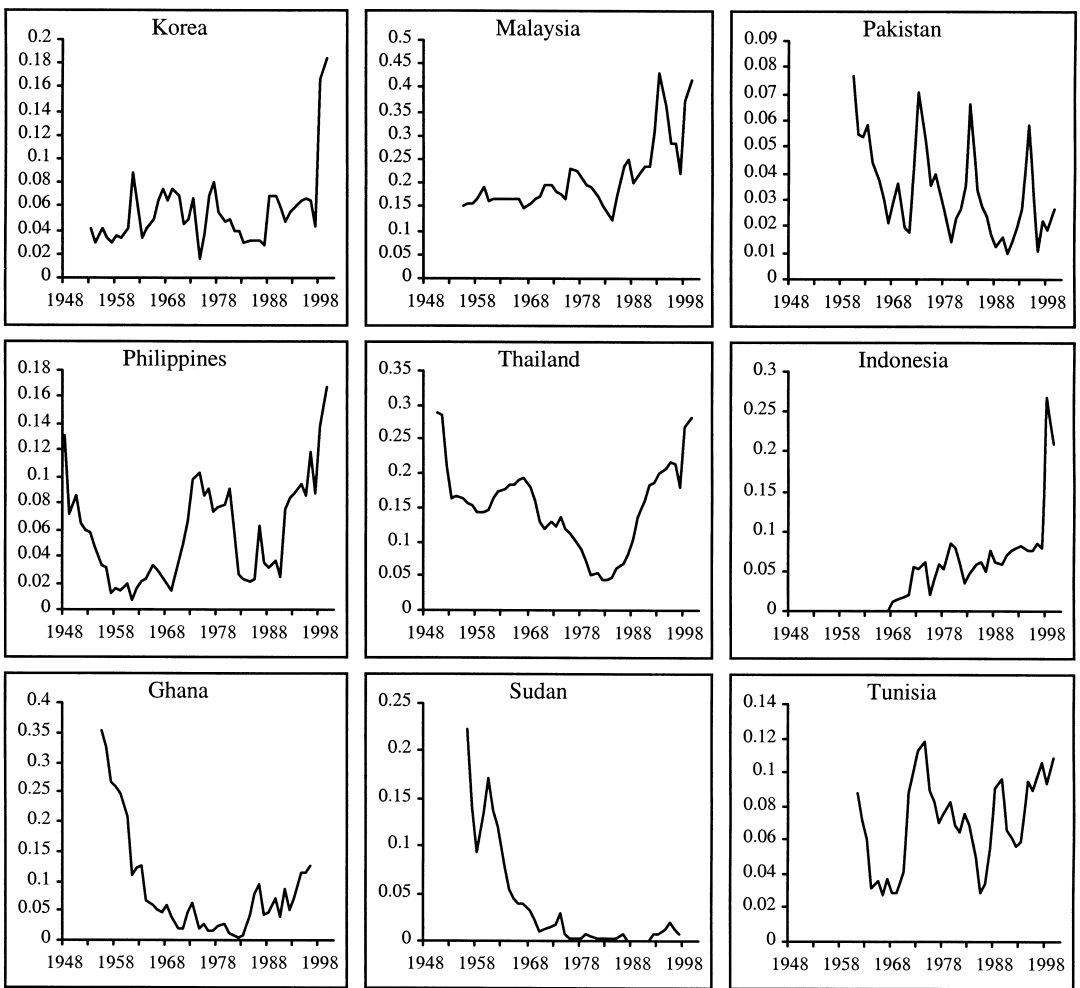

Source: Authors' calculations using data from the IMF's International Financial Statistics. Details can be found in appendix B.

reserve holdings that minimizes its total expected costs. The model identifies two costs incurred by the reserve authority. The first is the opportunity cost of holding reserves. The second is the adjustment cost that is incurred whenever reserves reach some lower bound. The adjustment cost is interpreted generally to be the output or welfare forgone by having to take other, costly policy measures to generate the external payments surplus necessary for reserve accumulation.

The two costs are interrelated since a higher stock of reserves reduces the probability of having to adjust and thus reduces the expected cost of adjustment, but this benefit comes at the cost of higher forgone earnings. Optimal reserve management involves finding the cost-minimizing level of reserves to acquire once reserves have reached their lower bound. Recall that the basic 
Table 1. Reserves Including Gold by Country Category

$\underline{\text { Period averages }}$

\begin{tabular}{lcccc}
\hline Category & $1948-1970^{a}$ & $1971-1980$ & $1981-1990$ & $1991-1999$ \\
\hline As a percentage of GNP (\%) $^{\text {all }}$ & 8.2 & 7.6 & 6.6 & \\
developed $^{\mathrm{b}}$ & 9.3 & 7.3 & 7.0 & 10.5 \\
developing $^{\mathrm{d}}$ & 7.3 & 7.8 & 6.3 & 12.4 \\
emerging $^{\mathrm{e}}$ & 5.5 & 5.8 & 6.0 & 14.9 \\
$\begin{array}{l}\text { In weeks of import cover } \\
\text { all }\end{array}$ & 22.5 & 17.9 & 15.4 & 20.6 \\
developed & 23.0 & 16.1 & 13.9 & 16.6 \\
developing & 22.1 & 19.2 & 16.4 & 23.3 \\
emerging & 19.7 & 19.7 & 17.6 & 27.6 \\
As a percentage of M2 & & & & \\
all & 31.3 & 20.5 & 15.2 & 21.2 \\
developed & 17.8 & 12.0 & 11.7 & 11.3 \\
developing & 37.7 & 25.1 & 17.1 & 26.6 \\
emerging & 28.7 & 23.5 & 19.1 & 29.9 \\
\hline
\end{tabular}

a. Coverage for developing and emerging economies over the $1948-1970$ period is incomplete.

b. The category "all" includes data for fifty-six countries. This category is separated into twenty-two developed countries and thirty-four developing using the IMF classification in 1979.

c. Developed countries are: United Kingdom, Austria, Belgium, Denmark, France, Germany, Italy, Netherlands, Norway , Sweden, Switzerland, Japan, Finland, Greece, Iceland, Ireland, Portugal, Spain, Australia, New Zealand, South Africa, and Canada.

d. Developing countries are Argentina, Brazil, Chile, Colombia, Costa Rica, Dominican Republic, El Salvador, Guatemala, Honduras, Mexico, Nicaragua, Panama, Paraguay, Peru, Venezuela, Jamaica, Israel, Jordan, Egypt, Mynamar, Sri Lanka, China, India, Korea, Malaysia, Pakistan, Philippines, Thailand, Indonesia, Hong Kong, Ghana, Sudan, Tunisia, and Turkey.

e. The category of emerging markets in the 1990s is made up of the following ten countries: Brazil, Chile, Colombia, Hong Kong, Korea, Mexico, Peru, Philippines, South Africa, Thailand.

idea in inventory management models is to optimize the trade-off between flow holding costs and fixed restocking costs.

Miller and Orr were the first to model desired money holdings in a stochastic inventory-theoretic framework. ${ }^{23}$ Frenkel and Jovanovic applied this inventory-theoretic approach to international reserve management. ${ }^{24}$

Frenkel and Jovanovic (FJ) hypothesized that reserve movements between the occasional restockings are generated by an exogenous Wiener process, where the incremental change in reserves in a small time interval is distributed normally. ${ }^{25} \mathrm{FJ}$ also assumed that the deterministic part of the incremental

23. Miller and Orr (1966). The basic (nonstochastic) model of the demand for money was developed by Baumol (1952) and Tobin (1956).

24. Frenkel and Jovanovic (1981).

25. Hamada and Ueda (1977) treated reserves as a random-walk process between restocking periods. A random-walk process is the discrete-time analogue to the continuous time Wiener process. Kenen and Yudin (1965) also specified reserves as a random-walk process. In addition, they suggested that central bank reserve holdings are sensitive to the volatility in the balance of payments rather than the absolute size of the gap between international payments and receipts, as in Heller (1966). Claassen (1965) used an inventory model of international reserve choice to clarify the nature of restocking costs. 
change in reserves is a negative drift while the stochastic part is without drift. They set the lower bound for reserves at zero.

In the special case of no reserve drift between stock adjustments, a secondorder Taylor-series approximation of optimal reserve holdings yields the following equation for reserves:

$$
R_{0}=\sqrt{\frac{C \sigma}{r^{0.5}}}
$$

where

$R_{0}$ : optimal starting level for international reserves after restocking

$C$ : country-specific nominal constant capturing the fixed cost of adjustment

$\sigma$ : standard deviation of the Wiener increment in the reserves time-series

process operating between stock adjustments

$r$ : opportunity cost of holding reserves.

Equation (1) shows that in the buffer stock model, optimal reserve holdings increase with the volatility of reserves $(\sigma)$. Higher volatility means that reserves hit their lower bound more frequently. The reserve authority is therefore willing to restock a larger amount of reserves and tolerate greater opportunity costs in order to incur the adjustment cost less frequently. Equation (1) also shows that a bigger adjustment cost increases optimal reserve holdings while a higher opportunity cost reduces them.

Equation (1) is expressed in the familiar square-root form. More useful for empirical work is the log transformation:

$$
\ln R_{0}=c_{0}+0.5 \ln \sigma-0.25 \ln r .
$$

In their empirical work, FJ turned equation $\left(1^{\prime}\right)$ into an estimating equation that is amazingly successful. A key step in taking equation ( $\left(1^{\prime}\right)$ to data is the additional assumption that observed reserves, $R_{t}$, are proportional to optimal reserves up to an error term that is uncorrelated with $\sigma$ and $r$. Hence,

$$
R_{0}=B R_{t} e^{-u_{t}}
$$

The estimating equation becomes: ${ }^{26}$

$$
\ln R_{t}=b_{0}+b_{1} \ln \sigma_{t}+b_{2} \ln r_{t}+u_{t} .
$$

26. In data, of course, $R_{0}=B R_{t} e^{-u_{t}}$ need not hold. We return to this point below. 
In equation (2), international reserves are defined as the sum of gold, SDRs, foreign exchange, and reserve position at the IMF. FJ defined $R$ in nominal terms. They generated $\sigma$ by computing for each year the standard deviation over the previous fifteen years of the trend-adjusted annual changes in the stock of international reserves. To obtain a variability measure that was free of scale, FJ divided the standard deviation by the value of imports. The opportunity cost of holding reserves, $r$, was approximated by a country's government bond yield. The constant $b_{0}$ is interpreted to be country specific and regime specific. It is nominally denominated and incorporates country-specific adjustment costs and the possibly country-specific proportionality factor, $B$.

In their work, FJ, and later Frenkel, estimated equations exactly and closely related to equation (2) using ordinary least squares on various cross-section and panel data sets..$^{27}$ Before we begin to replicate, update, and modify their work, we highlight one equation estimated in Frenkel and Jovanovic across twenty-two developed countries over the $1971-75$ period: ${ }^{28}$

$$
\begin{gathered}
\ln R_{t}=b_{0}^{i}+0.505 \ln \sigma-0.279 \ln r \\
(0.110) \quad(0.149) \\
R^{2}=0.97, \mathrm{n}=110, \text { S.E. }=0.234,
\end{gathered}
$$

where (OLS) standard errors are in parentheses and the country-specific constant terms range between 3.42 and 6.78. By the standards we are used to in international macroeconomics, the above equation is nothing short of miraculous. The estimated elasticities of reserve holdings with respect to $\sigma$ and $r$ are very close to the predictions of the theoretical model given by equation $\left(1^{\prime}\right)$.

We now try to replicate the FJ regression in equation (3) using revised data from the IMF's International Financial Statistics. Our replication will not be exact because of a scaling issue. Many early estimates of reserve holdings included a scale variable such as income or imports as a separate regressor. From equation (1), we know that under the null, when we scale $R_{t}$ by $Y_{t}$, for example, then we scale the right-hand side such that

$$
R_{t} / Y_{t}={\sqrt{\frac{\left(C_{t} / Y_{t}\right)\left(\sigma_{t} / Y_{t}\right)}{r^{0.5}}}}^{29}
$$

27. Frenkel (1983).

28. Countries included in the regression are listed at the bottom of table 2. All data used by FJ were taken from the IMF's International Financial Statistics.

29 . Note that our specification now sets $C=C_{t}$, which we implicitly hypothesize to be pro- 
We therefore scale the dependent variable as well as the volatility measure and (implicitly) the constant term, rather than adding a separate scaling regressor.

We reestimate equation (2) trying several different scaling variables. Table 2 reports results using four of them: none, real (price level), GNP, and (nominal) imports. All of the equations are estimated with and without country fixed effects and they are estimated over three different periods, 1971-75 (as in FJ), 1976-97, and 1971-97.30

We interpret our replication results in table 2 as consistent with those of FJ; our approach differs from theirs primarily in that we use different scaling methods and we calculate generalized method of moments (GMM)-style standard errors for estimated coefficients. In our replication reserve volatility still positively influences reserve holdings, with an elasticity of 0.5 or more in almost all of the regressions. The interest rate has a negative and significant coefficient in all regressions with no fixed effects, but with fixed effects, this coefficient is neither reliably negative nor significant in the later sample periods. Finally we note from comparing the adjusted $R^{2}$ 's of the fixed-effects regressions with those of the no-fixed-effects regressions that the nonconstant explanatory variables are consistently picking up 15 percent to 50 percent of the variation of the dependent variables. Further, with one exception, the point estimates of $R^{2}$ rise between the earlier and later sample periods for the nofixed-effects regressions. The $R^{2}$ estimates fall for the later sample periods once fixed effects are included.

The FJ-style reserve equations have, in our view, held up well when confronted with new data. However, we have some reasons to be unsure about our interpretation of these results.

\section{Rethinking the Empirical Implementation of the Buffer Stock Model}

Under the FJ null hypothesis, international reserves follow a Wiener process until they hit the lower boundary, which is zero. Then, in a one-step adjustment, reserves jump back up to their optimal restocking level and commence once again to follow the Wiener process.

portional to whichever scaling variable we use. Recall that $C$ has nominal units in the FJ model, so it makes sense that it be proportional to a nominal quantity.

30. Frenkel (1980), using a similar reserve-holding equation, found a structural break around the demise of Bretton Woods in 1971-73. Lizondo and Mathieson (1987) found another structural break around the 1982 international debt crisis. We ignore these breaks. 


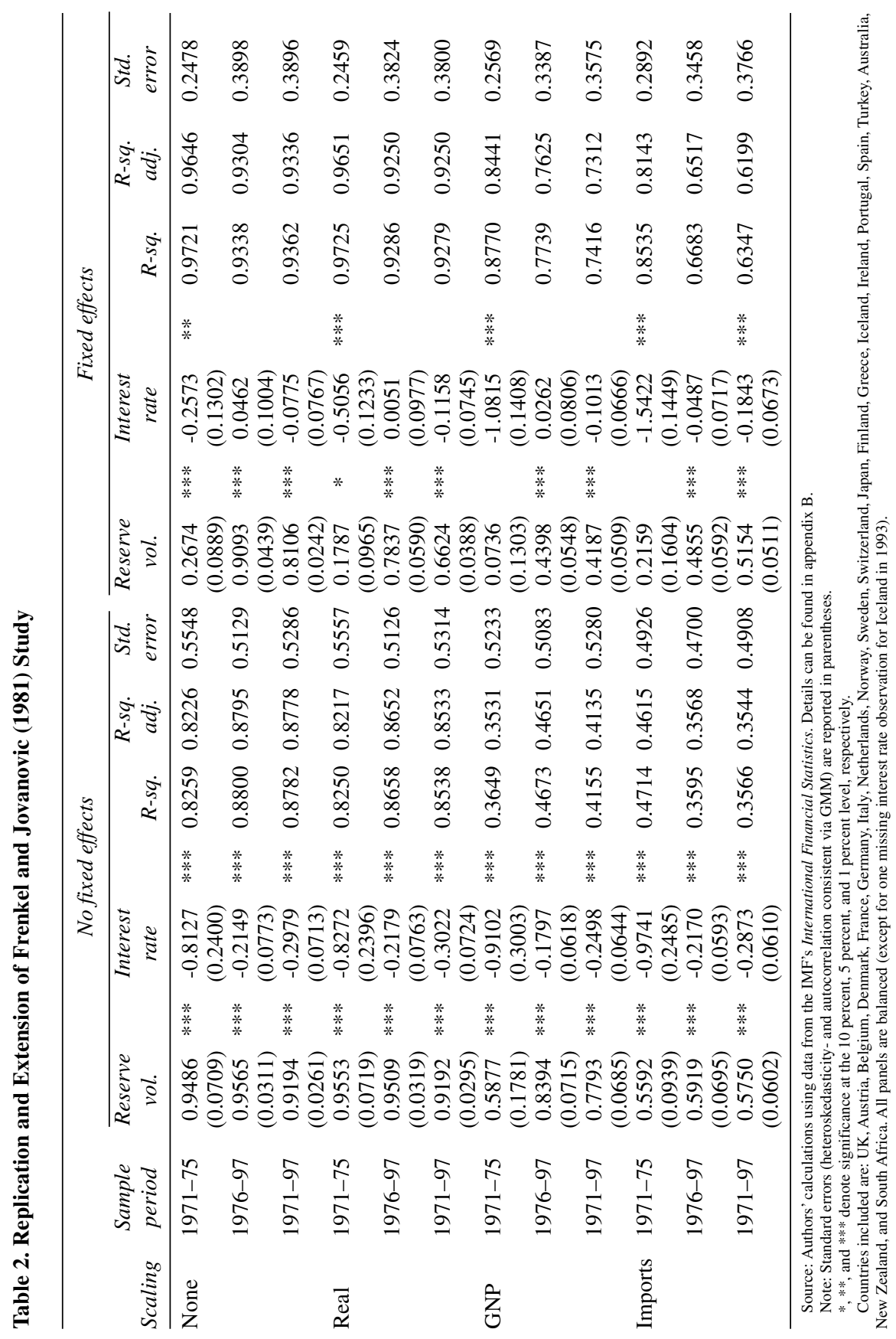


In empirical applications, Frenkel and Jovanovic constructed a measure of reserve volatility using a fifteen-year rolling standard deviation, with no attempt to separate typical incremental volatility (the Wiener increments) from the relatively large upward restocking adjustments that take place from time to time under the null hypothesis. ${ }^{31}$ Indeed, there is nothing in widely used reserve data sources (for example, International Financial Statistics (IFS)) that allows researchers to separate private-sector-induced reserve increments from the reserve-management authorities' adjustments. Including the big upward adjustments imparts possible positive skewness to the reserve increments measure (under the null) and leads to a potential upward bias in the estimated coefficient on volatility. A simple example of this bias is provided in appendix C. The potential upward bias is an important issue. The primary research objective of the buffer-stock models is to estimate the extent to which volatility matters for reserve holdings. ${ }^{32}$

Skewness induced by periodic adjustments by the reserve authority is potentially serious, but it is only part of the problem. The data that FJ studied were generated largely during an era of relatively low capital mobility, with few speculative attacks in the data and no models of speculative attacks in the literature. The speculative attack models of Salant and Henderson and Krugman were very new when FJ wrote. ${ }^{33}$ The models, however, were prophetic for reserve movements after 1980. Large modern-day reserve increments seem about as likely to be generated by speculative attacks (big downward shocks) as by occasional macro-based restocking of reserve inventories.

We thus confront two difficulties. First, currency and financial crises generate large negative reserve increments before reserves hit their lower bound, violating the assumption that reserves follow a Wiener process up until they hit the barrier. Crises impart negative skewness to the reserve increment measure. Second, empirical methods that rely on multi-period rolling averages to calculate reserve volatility will capture the large positive reserve increments that characterize reserve restocking. Including the restocking increments imparts positive skewness to the reserve increment measure. If we, as researchers, were really lucky, the two types of big reserve shocks would just

31. Other researchers used different measures for the rolling reserve-increment standard deviation. See, for example, Lizondo and Mathieson (1987).

32. FJ acknowledged the problem associated with reserve-increment measurements. In a footnote, they wrote: "Since we do not know the exact time at which actual adjustment took place, it is possible that our proxy of $\sigma$ is biased upwards, since it may reflect, in part, reserve changes that are associated with a recent adjustment" (FJ, 1981, p. 510).

33. Salant and Henderson (1978); Krugman (1979). 
cancel out and we could proceed to update FJ's work for the 1980s and 1990s, blithely ignoring these skewness issues.

As a check on the data to see if we did, indeed, get lucky, we measured the skewness of monthly reserve increments using Pearson's skewness statistic for sixty-eight individual countries over different time periods. We found that skewness is idiosyncratic by country and time period. During the FJ period of 1971-75, 36 percent of the countries showed significant positive skewness and 11 percent showed negative skewness. In the 1982-97 period those percentages became 41 percent and 21 percent, respectively. ${ }^{34}$

We interpret these data as telling us that the reserve increment process is complicated. In statistical terms, the process is apparently a mixture of typical increments - possibly distributed conditionally normally — plus some sort of endogenous jump process. The jumps down are associated with speculative attacks on reserve stocks and the jumps up represent macro-policy changes that induce reserve accumulation.

Since the 1971-75 period examined by FJ was dominated by positive skewness in the reserve increments, that skewness imparts a positive bias to the coefficient on reserve volatility. Moreover, extending the window used to construct the volatility measure can compound this bias.

For example, using the unscaled Frenkel and Jovanovic regression, when three years is chosen as the window for constructing the volatility measure, the coefficient on reserve volatility is insignificantly different from zero. As the window is extended, the coefficient becomes increasingly positive and more significant. For the FJ regression scaled by GNP, a similar pattern emerges. These results are consistent with an interpretation that attributes the positive correlation between reserve holdings and their volatility to positive skewness in the reserve increment data.

We reestimated the FJ regression for the sample period 1971-75, controlling for the degree of skewness with an interactive dummy on the volatility coefficient that varies according to whether the country had negative skewness, positive skewness, or no skewness in its reserve increments during the period. While the results are consistent with the view that skewness affects the estimated coefficient on volatility, they are not very reliable because of the small number of countries in each of the skewness categories.

34. These data are available from the authors. We also examined annual reserve-increment skewness. As expected, skewness is less dramatic statistically when increments are constructed from more aggregated annual data. 
Once we begin to account for endogenous and discrete reserve jumps (from attacks and policy changes), the statistical process governing the evolution of reserves becomes quite different from the process assumed by FJ and the FJ derivation of optimal behavior would not apply. Fortunately we can, in theory, sidestep the statistical issues associated with reserve increment distributions by shifting attention to movements of a variable invented after FJ wrote, "the shadow exchange rate."

The shadow exchange rate is the exchange rate that would be determined in the foreign exchange market if foreign exchange reserves were exhausted and the exchange rate were allowed to float freely. Let $\tilde{S}$ be the shadow exchange rate defined as the price of foreign exchange (reserves) and suppose that $\bar{S}$ is the nonfree-floating exchange rate with reserves above their lower boundary and some foreign-exchange intervention using the reserve stock. Regardless of the specific policy governing $\bar{S}$ (for example, perhaps $\bar{S}$ is constant), if $\tilde{S}$ were to drift above $\bar{S}$ then speculators seeking capital gains would try to purchase the remaining reserves devoted to the current policy in a speculative attack and force a policy adjustment. ${ }^{35}$ Thus, regardless of the value of reserves or other variables, the probability of reserves hitting their lower bound is identical to the probability of $\tilde{S}$ hitting $\bar{S}$ from below.

In the next section, we make a case for replacing Frenkel and Jovanovic's reserve-increment volatility measure with our own model-specific volatility measure. Since reserve increments are endogenous to optimal reserve management, to speculative attacks and to many aspects of private behavior, we end up replacing the volatility of these increments that are endogenous under the null with an equivalent volatility measure that is a function of variables that logically may be maintained to be exogenous under the null. We identify economic fundamentals that drive the shadow exchange rate to its upper bound at the same instant that reserves are driven to their lower bound. Our volatility measure is then the volatility of these fundamentals.

35. In an attack, speculators purchase reserves at $\bar{S}$ with the hope of selling them for a capital gain at a higher $\tilde{S}$. Speculative attacks of this nature were introduced by Salant and Henderson (1978) and applied to the foreign exchange market by Krugman (1979) and Flood and Garber (1984). The shadow rate-related attack mechanism is adapted easily to later "generation" speculative-attack models. See, for example, Flood and Marion (1999). 


\section{The FJ Inventory Model and the Shadow Exchange Rate}

By assuming that reserve increments follow a Wiener process, FJ avail themselves of many well-known results. They proceed formally by assuming that reserves have just been reset at their optimal point and the restocking costs have just been paid. The problem for the reserve authority is then to estimate future costs so as to balance appropriately the fixed costs of restocking against the holding costs of reserve inventories. Future costs can be separated into two components, (a) the holding costs incurred up to the next optimal restocking, and (b) the costs incurred following the next restocking decision.

To calculate the expected present value of the holding costs up to the next restocking, the reserve authority must determine the probability that as of time $t$ reserves have not hit the lower boundary since time 0 , when they were reset at their optimal level. The authority must also determine the expected value of reserves at time $t$ conditional on reserves not having passed through the lower boundary between time 0 and time $t$.

The expected present value of costs following the decision to restock is just the fixed adjustment cost of the next restocking plus all future holding and restocking costs. Its calculation requires knowledge of the probability that at time $t$ reserves pass through the lower boundary after starting at their optimal level at time 0 .

The analogy between the reserve process and the shadow exchange-rate process is straightforward. The probability that as of time $t$ reserves have not hit the lower boundary since time 0 , when they were set optimally at $R_{0}$, is also the probability that $\tilde{S}$ has not hit $\bar{S}$ in that same time interval. The probability that $R$ passes the lower boundary at $t$ after starting at $R_{0}$ is also the probability that $\tilde{S}$ hits $\bar{S}$ at $t$ when reserves start at $R_{0}$. Finally, since the expected value of reserves conditional on their not having hit the lower boundary depends only on $R_{0}$ and the distribution of the reserve increments, it also depends on $R_{0}$ and the distribution of the (maintained exogenous) fundamentals that influence the shadow rate.

Appendix $\mathrm{C}$ presents a model that identifies the (exogenous) economic fundamentals determining the shadow exchange rate. We can then use the distribution of these fundamentals to construct a new volatility measure. 


\section{A Test of the Buffer Stock Model Using a New Volatility Measure}

This section estimates several versions of the reserve-holdings equation derived from the buffer stock model using our new volatility measure. In none of our work do we model time-series processes for the error terms of our estimating equations or specify partial-adjustment models. Instead, we report GMM-style standard errors that are robust to heteroskedasticity and serial correlation.

The model we estimate involves variations of the following equation:

$$
\ln \left(R_{t} / X_{t}\right)=\beta_{0}^{i}+\beta_{1} \ln \left(\sigma_{t} / X_{t}\right)+\beta_{2} \ln \left(i_{t}\right)+u_{t},
$$

where

$R$ : level of reserves

$X$ : scale variable taking on one of five values: unity (or "None"); the price level (or "Real"); GNP; the nominal value of imports (or "Imports"); and M2

$\beta_{0}^{i}$ : coefficient on country $i$ 's fixed-effects dummy

$\sigma$ : volatility. It is measured as the standard deviation of the previous two years of monthly shocks to the shadow-rate fundamentals' time series process, which is assumed to be a random walk with drift.

$i=(1+r) /\left(1+r^{*}\right): r$ and $r^{*}$ are domestic (no *) and U.S. $\left(^{*}\right)$ money market, Treasury bill, deposit, lending, or government bond rates.

In the previous section we discussed the rationale for the fundamentals volatility measure in equation (4). We now turn our attention to the opportunity-cost regressor.

In the early literature, the opportunity cost variable (proxied by the owngovernment bond rate in the FJ estimation of developed countries' reserve holdings) was difficult to measure exactly and was generally not a significant variable. Consequently, it was often left out of estimating equations for reserves. For developing countries, interest rates were government controlled rather than market determined, so an opportunity cost measure based on interest rates was not meaningful. Kenen and Yudin suggested that the opportunity cost of holding reserves was not lending them for capital formation, so the opportunity cost should be measured by the marginal product of capital. ${ }^{36}$ (The interest earned on reserves was ignored since it was likely to be small and stable.)

36. Kenen and Yudin (1965). 
Since in theory GNP is inversely related to the marginal product of capital, they suggested that a per capita income measure could proxy for the opportunity cost. ${ }^{37}$ Edwards, studying the problem twenty years later, was able to obtain interest-rate data for seventeen developing countries that borrowed in the Eurocurrency market. ${ }^{38} \mathrm{He}$ used the difference between the interest rate faced by these countries in the Eurocurrency market and LIBOR as his measure of opportunity cost and found that it had a significant, negative effect on reserve holdings, just as the inventory model would predict.

In the 1990s, many emerging markets liberalized their economies and moved to market-determined interest rates. We take advantage of the interestrate data available from this decade so that we can calculate our opportunity cost measure. ${ }^{39}$ Our measure is the difference between domestic and U.S. interest rates on government bonds (or Treasury bills, money market, or lending and deposits).

We now proceed to estimate reserve holdings using our new volatility and opportunity cost measures. Panel data for thirty-six developed and developing countries over the 1988-1997 period are used. Our purpose is to uncover whether reserve holdings over that ten-year period are sensitive to volatility in the macroeconomic environment; that is, the volatility in the fundamentals driving the shadow exchange rate. We also wish to learn whether reserve holdings vary negatively with their opportunity cost, measured as a standard interest-rate differential. Results are reported in table 3. We also include in the table results using the FJ reserve volatility measure (now based on the previous two years of monthly shocks to the reserves process).

That table is divided into ten parts, corresponding to each of our five scaling methods with and without country fixed effects. For explanation, first turn to the top, left-hand part of the table-scaling is none for both the dependent variable and the volatility measure. The first two rows give results using the new fundamentals volatility measure. The next two rows show results using

37. The results using the income proxy were disappointing. In later studies, GNP was used as a scaling variable or to represent the transactions demand for money by a central bank. In some studies, an income term was added as part of a specification of disequilibrium in the money market that would affect the slow adjustment of reserves to their desired level.

38. Edwards (1985).

39. Interest is earned only on the nongold holdings of central bank foreign-exchange reserves. It will not matter too much that we do not decompose each country's reserves into gold (which earns no interest) and foreign-exchange reserves. Nor will it matter much that we do not specify the currency composition of foreign-currency reserves. That is because the interest rates on U.S., European, and Japanese short-term government bonds, which are the preferred instruments for official foreign-exchange holdings, are small and stable and dominated by movements in own-government bond yields. 


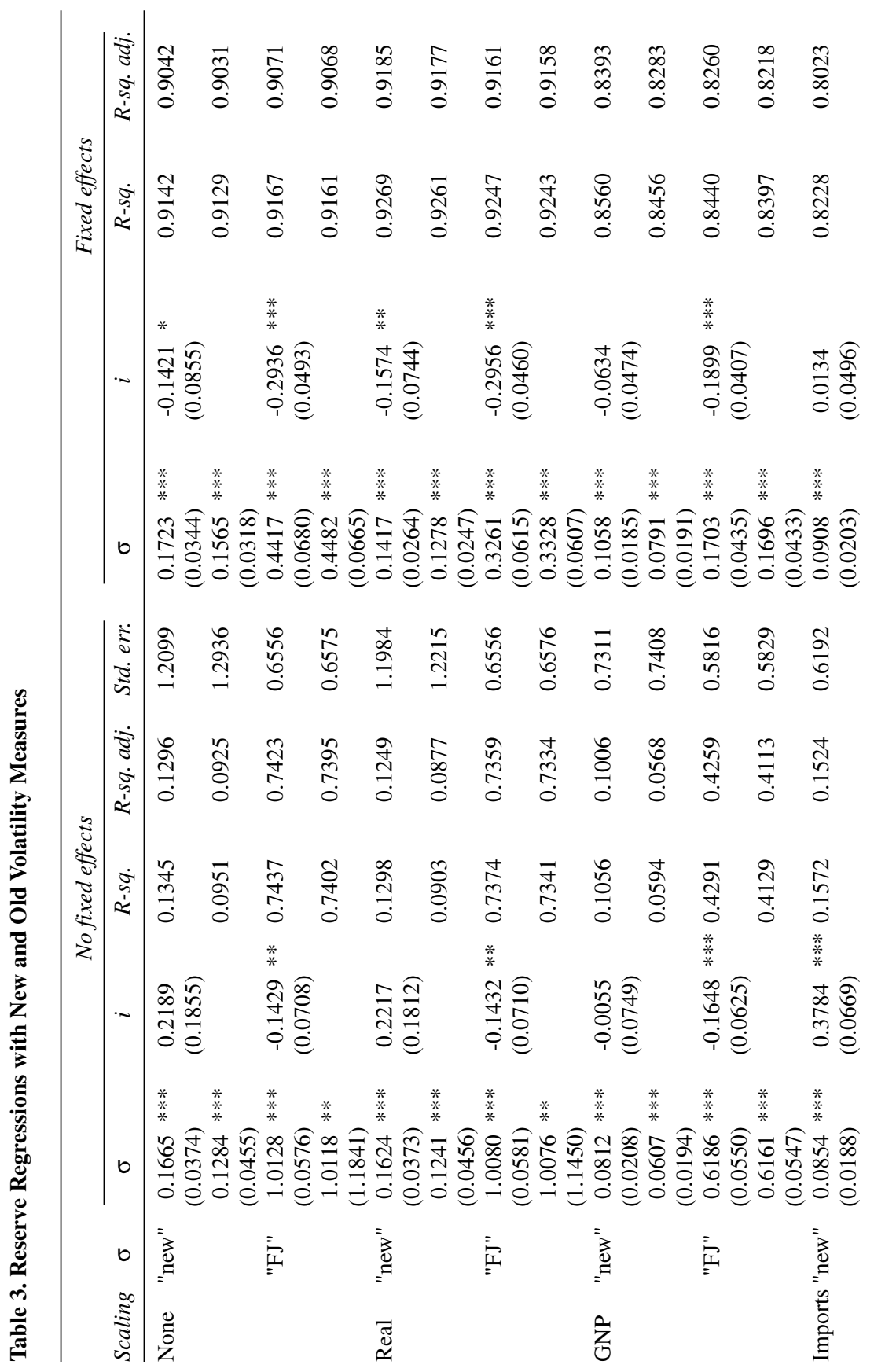




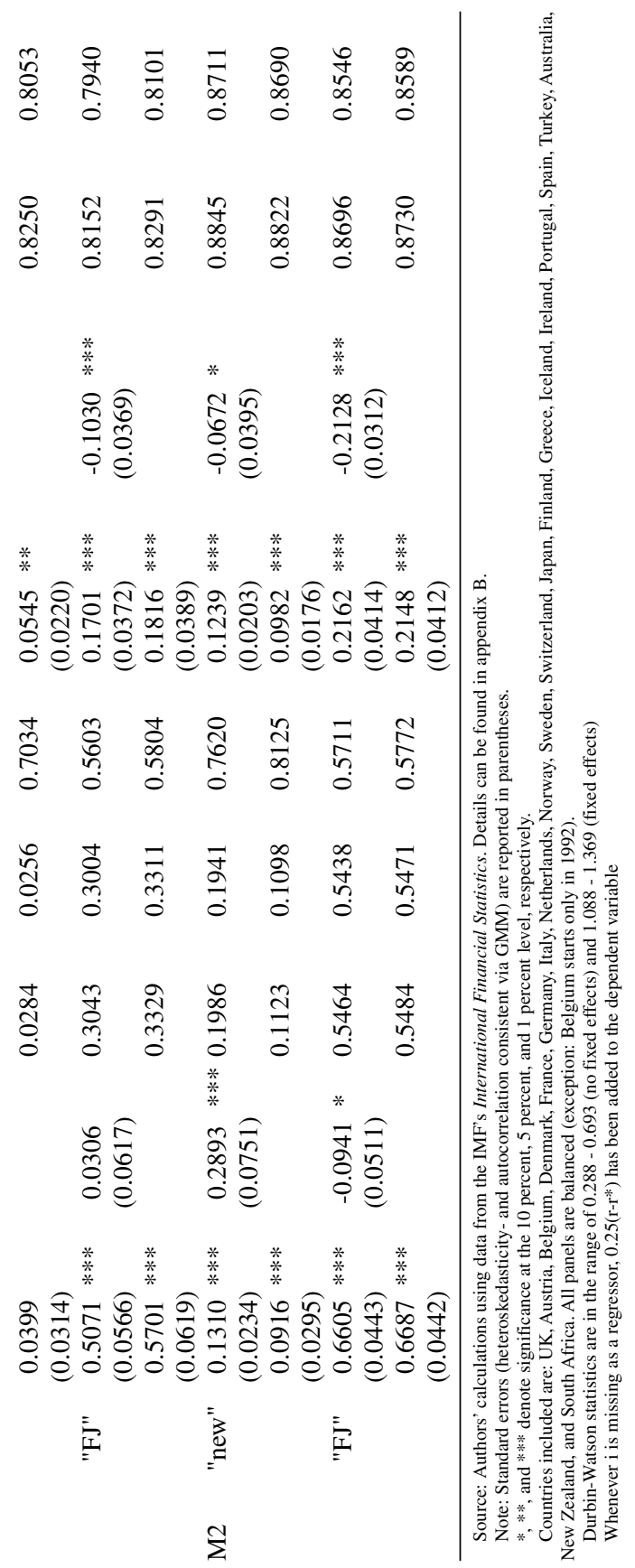


the FJ reserve volatility measure. Recall that the FJ measure contains skewed increments that interact with measurement error in the dependent variable to impart a positive bias to the estimated coefficient on volatility. Estimation in the top left-hand section is without fixed effects.

In the first line of that section, the estimated coefficient on $\ln \sigma$ is 0.1665 and is highly significant. The coefficient on $\ln i$ is 0.2189 but is not significant. These variables produce an adjusted $R^{2}$ of 0.1296 . Since it is difficult to find instruments for a plausibly endogenous opportunity cost, and the coefficient on the opportunity cost is not significant, we also try constraining the coefficient to be -0.25 as the theory suggests, then adding the constrained opportunity cost to the dependent variable. The results of that experiment are reported in the second row of the top left section and consequently indicate no estimated coefficient for the opportunity cost variable. The coefficient on the new volatility measure continues to be highly significant, although its size is reduced by about one standard deviation.

In the same section, note that for the unscaled Frenkel and Jovanovic regressions, the coefficient on the reserve volatility measure is highly significant, although much larger than theory would suggest, and the coefficient on the opportunity cost is significant and has the expected negative sign. Using the old reserve volatility measure obviously inflates the adjusted $R^{2}$. Since the equations in the upper left-hand part of the table involve a dependent variable that is trending in our sample, we prefer to jump to another section of the table before further interpreting our results.

In the third section of table 3, where reserves and volatility are scaled by GNP, we see that our new volatility measure is again highly significant with and without fixed effects and whether or not the opportunity cost coefficient is constrained. The estimated coefficient on the opportunity cost is negative but always insignificant when left unconstrained. ${ }^{40}$ The other sections of the table reveal that the coefficient on volatility is highly significant regardless of scaling or the addition of fixed effects.

As with the FJ regressions, we investigated the panel further according to a higher moment measure and looked at some alternative volatility windows. For FJ we categorized countries according to skewness. For fundamentals

40. In all estimations we have used the interest rate differential, $\ln \left((1+i) /\left(1+i^{*}\right)\right)$, as the opportunity cost of reserve holding. We also estimated reserve-holding equations with the realized excess return, $\ln \left((1+i) * S[t] /\left(1+i^{*}\right) S[t+1]\right)$, as the opportunity cost variable. This variable replacement did not improve the fit of the estimated equations nor did it solve the problem of finding useful instrumental variables for the opportunity cost. Counting capital gains from devaluation on the books of the reserve-management authority also sets up odd incentives. 
volatility, the appropriate analog is coskewness. ${ }^{41}$ We divided the sample on the basis of coskewness into three equal-sized parts and then estimated the regression scaled by GNP with three separate coefficients on fundamentals volatility corresponding to our three-way coskewness breakdown. The three coefficients were always significant at the 1 percent level and equality of the coefficients could not be rejected at the 10 percent level.

We also experimented with different "volatility window" sizes. When we varied the window for calculating reserve volatility, we obtained results consistent with the FJ equation being subject to skewness bias. In table 3, the fundamentals volatility is constructed from a window containing the most recent two years of monthly fundamentals innovations. As an additional check to see if our results might be due to coskewness, we re-estimated variously scaled versions of equation (4) using volatility windows of twelve, twentyfour, thirty-six, and forty-eight months for constructing our volatility measure. We found that the estimated coefficients on the volatility measure were very similar numerically and statistically significant regardless of window size. Our finding is consistent with no effect from coskewness.

We also tested how well the fixed-effects version of the estimating equation (4) forecasted out-of-sample. Using available data to construct fundamentals volatility and the opportunity-cost measure for 1998 and 1999, we were able to compute predicted reserve holdings for some countries and for some versions of scaled reserves in 1998 and 1999. We then compared these predicted values to actual reserve holdings over the same period. We found that the equation did reasonably well at forecasting on average, but it tended to underestimate reserve holdings in 1998 and 1999 for emerging markets such as South Korea, Mexico, and Israel, and overestimate reserve holdings for several industrialized countries, such as Canada, and for Brazil, an emerging market that ran into difficulties in the late 1990s. ${ }^{42}$

Summarizing our results, we see from table 3 that when equation (4) is estimated on data for the 1990s, volatility always has a positive and highly significant effect on reserve holdings. This result holds regardless of scaling and whether or not fixed effects are added. When we constrain the coefficient on the opportunity cost to be consistent with the null, volatility is still highly significant in nine out of ten runs.

41. See appendix $\mathrm{C}$ for elaboration.

42. Disyatat and Mathieson (2001) estimated an FJ-type reserve-holding equation for fifteen Asian and Latin American countries and found that the financial crises in 1997-98 produced no clear structural break. They did find that reserve holdings were more sensitive to reserve volatility after the Asian crisis. 
When we started our investigation of the FJ buffer-stock reserve equations, we suspected the well-known results to be too good and due, perhaps, to a statistical anomaly. We have been unable to overturn them, however. International reserve holdings increase with volatility, even in a world of high capital mobility. The prediction of the buffer stock model that says reserve holdings should decline with increasing opportunity costs does not hold up as well-it never has. The coefficient on the opportunity cost measure is not reliably negative and significant.

Comparing the adjusted $R^{2}$ of equation (4) with and without fixed effects, we note that the fixed effects pick up about 75 percent of the cross-country variation in reserve holdings. That leaves 25 percent to be explained and we pick up almost one-half of that with our volatility and opportunity cost measures. That said, the volatility and opportunity cost measures together explain only about 10 percent to 15 percent of the variation in reserve holdings. By most standards, their explanatory power is low. Yet it is comparable to the ability of empirical models to explain movements in nominal exchange rates.

Unfortunately, the buffer stock model does not provide guidance about the nature of the adjustment costs captured by the fixed effects. To say that the fixed effects explain about 75 percent of the variation in cross-country reserve holdings does not advance our understanding very much. Next, we explore some research directions in an attempt to learn more about these fixed effects.

\section{Extensions}

A country's exchange-rate policy is generally thought to affect its reserveholding behavior. It has long been assumed that countries with fixed or heavily managed exchange rates must be prepared to intervene in the foreign-exchange market and so will hold more reserves than countries with more flexible exchange-rate policies. Frenkel and Edwards found some supporting evidence for this view. ${ }^{43}$

To take account of a country's degree of exchange-rate flexibility, we add a control to our estimating equation (4). The control is the standard deviation of the innovation to the percentage change in the nominal effective exchange rate. Since this volatility measure is already in percentage terms, it is not scaled. The idea behind using this control is that the greater the degree of exchangerate flexibility, the lower the adjustment cost if reserves should hit their lower

43. Frenkel $(1974,1980)$ and Edwards (1983). 
bound. Consequently, we would expect greater exchange-rate flexibility to be associated with lower reserve holdings.

A country's openness may also affect its reserve-holding behavior. In the early literature, Heller reasoned that in the absence of reserves, any temporary deficit in the balance of payments would have to be corrected via a reduction in aggregate expenditures. ${ }^{44}$ The required change would be smaller, the higher the propensity to import. He concluded that an increased propensity to import, by reducing the adjustment cost, would be negatively related to reserve holdings. Frenkel and others interpreted the propensity to import as measuring the economy's openness and hence its vulnerability to external shocks. ${ }^{45}$ Since a more open economy could face more frequent adjustment costs, greater openness would be associated with higher reserve holdings. In that case, reserve holdings should be positively related to the import propensity. In empirical work, researchers substituted the average propensity to import for the marginal propensity because of data limitations and often found it to be positively correlated with reserves.

The currency and financial crises of the 1990s raise the possibility that a country's openness on the financial side as well as its openness on the real side might affect its vulnerability to a crisis and the frequency with which it faces adjustment costs. In addition, openness may influence the size of those costs. If the adjustment cost is interpreted to be the output lost during a crisis, then a country with greater financial and real-side openness may face a steeper output decline. ${ }^{46}$ To the extent that financial and real-side openness increase both the size and frequency of the adjustment cost, they should be positively correlated with reserve holdings.

To take account of openness in our empirical work, we add a control for real-side openness, measured as the ratio of exports plus imports to GNP, and a control for financial-side openness, measured as the ratio of gross capital flows to GNP.

The results of adding only the effective exchange-rate volatility control are disappointing. The coefficient on exchange-rate volatility is negative and significant when the estimating equation is scaled by "None," "Real," or "GNP," supporting the view that countries with a more flexible exchange rate hold fewer reserves. However, the coefficient is not significant when the scaling is

44. Heller (1966).

45. Frenkel (1983).

46. Ben-Bassat and Gottlieb (1992) found a positive relationship between the average propensity to import and the output cost of an external default for a sample of fourteen default cases over the 1960-82 period. 
"imports" or "M2." More importantly, exchange-rate volatility never has any significant effect explaining reserve holdings over and above the explanatory power of country fixed effects. The adjusted $R^{2}$ with and without exchangerate volatility are nearly identical.

When both openness measures as well as exchange-rate volatility are added as controls, the results are more promising. When scaling is none, real, or GNP, each of the openness measures is positive and significant and exchange-rate volatility is negative and significant. ${ }^{47}$ Moreover, adding the three controls triples or quadruples the explanatory power of the buffer stock model without fixed effects.

An example of the regression results appears below, where scaling is GNP ( $\mathrm{X}=\mathrm{GNP}$ ), ERV is nominal effective exchange-rate volatility, FOP is financial openness and ROP is real-side openness:

$$
\begin{aligned}
\ln \left(R_{t} / X_{t}\right)= & \beta_{0}^{i}+0.0969 \ln \left(\sigma_{t} / X_{t}\right)+0.0048 \ln \left(i_{t}\right), \\
(0.0134) & (0.0387) \\
-1.7283 E R V_{t}+0.1059 \ln \left(F O P_{t}\right)+0.5335 \ln \left(R O P_{t}\right)+\mu_{t}, & (0.1667) \\
& (0.4418) \quad(0.0375) \\
\bar{R}^{2}= & .88 \quad n=333 \text { S.E. }=.2712
\end{aligned}
$$

GMM-type standard errors are in parentheses and there are country-specific constants. Even accounting for the fixed effects, the explanatory power of the regression is enhanced by the three controls. Without the fixed effects, the explanatory power quadruples, with fundamentals volatility, opportunity cost, and the three control variables together explaining 42 percent of the crosscountry variation in reserve holdings.

Country-specific characteristics probably account for differences in adjustment costs facing countries that run out of reserves. Our results suggest that financial and real-side openness as well as exchange-rate volatility are sensible candidates for helping to explain these differences.

47. The results are less satisfactory when scaling is imports or M2. There is also the question of whether the controls are completely exogenous. 


\section{Conclusion}

Three points should be emphasized. First, the buffer stock model of international reserve holding works about as well in the era of high capital mobility as it did when capital was less mobile. Its prediction that increased volatility significantly increases reserve holdings is very robust. While the model works well statistically, it explains very little about countries' reserve holdings — only about 10 to 15 percent. Most of the explanation in our regressions is due to country-specific fixed effects.

Second, country characteristics that might logically affect the cost of adjustment in the event of depleted reserves can improve the explanatory power of the buffer stock model. We have found that effective exchange-rate stability and a country's financial and real-side openness, together with volatility and opportunity-cost elements, can explain about 40 percent of the variation in countries' reserve holdings.

Third, empirical studies of optimal reserve holdings are hampered by the fact that the researcher does not observe optimal holdings, only actual holdings. Consequently, measurement error in the variable to be explainedoptimal reserve holdings - can interact with the constructed volatility measure to generate a misleading correlation between reserve holdings and volatility. A key prediction of the buffer stock model is that uncertainty influences optimal reserve holdings. Greater capital mobility in the 1990s, while beneficial in many respects, may have increased uncertainty in the international economy, in part by increasing the vulnerability of some countries to financial crises. It is important for researchers to test whether increased uncertainty helps explain increased reserve holdings. But they must do so in a way that keeps statistical biases to a minimum.

APPENDIX A

\section{Case Studies}

Many factors influence a country's decision to maintain a large reserve stockpile. This appendix examines the reserve patterns for Taiwan, South Korea, and China, three interesting case studies, and offers insight on the current record levels of world reserve holdings. 


\section{Taiwan}

Taiwan has the fourth-largest international reserve holdings in the world, just behind Japan, China, and Hong Kong. ${ }^{1}$ Most observers attribute Taiwan's large reserve stockpile to persistent current-account surpluses. ${ }^{2}$ The country has recorded a current-account surplus every year in the last two decades.

The dramatic buildup in Taiwan's reserves occurred in the mid-1980s, when Taiwan's current-account surplus as a share of GNP rose to 14.8 percent in 1985, 21.4 percent in 1986, and 18.3 percent in 1987. Capital transactions were strictly controlled at the time, and although the country had officially adopted a flexible exchange rate in 1979, exchange-rate movements were modest. In 1986 and 1987 the authorities intervened heavily to prevent a drastic appreciation of the currency in response to the current-account surpluses. Because of this intervention, reserves doubled in 1986, from $\$ 22.7$ billion to $\$ 46.5$ billion, and they increased by two-thirds in 1987 , to $\$ 77$ billion. (Despite this intervention, the New Taiwan dollar appreciated in nominal terms by over 35 percent against the U.S. dollar.) Since the undervalued domestic currency was contributing to the current-account surplus, exchange-rate policy was changed and the New Taiwan dollar was allowed to float. Since 1988 the central bank has intervened infrequently in the foreign-exchange market, doing so when political tensions escalate, as they did in 1991, 1994, 1999, and 2000. Each of those years saw reserve increases of 10 percent or more.

Taiwan has taken steps to liberalize capital movements, but there are still many restrictions, particularly on capital inflows. For instance, noninstitutional foreign investors were allowed to invest in its stock market starting only in 1996. On the eve of the Asian crisis (June 1997), Taiwan's private sector was a net foreign creditor, with foreign assets of $\$ 35.5$ billion and foreign debts of $\$ 30$ billion. Public foreign debt was negligible. Consequently, Taiwan did not face the adverse balance-sheet problems of its Asian neighbors. During the initial months of the Asian financial crisis, Taiwan intervened in the market to prevent its currency from depreciating, but it ceased intervention in mid-October 1997. Its reserve holdings fell by 5 percent that year. Since then they have resumed their upward climb. At the end of 1999, total reserves were equal to 36 percent of its GNP and accounted for fifty weeks of import cover.

1. Data used in the case studies are from the IMF's International Financial Statistics and from national central bank and government statistics publications.

2. See Kuo and Liu (1998). 
Figure A-1. Taiwan's Reserve Holdings

Total reserves (billions of dollars)

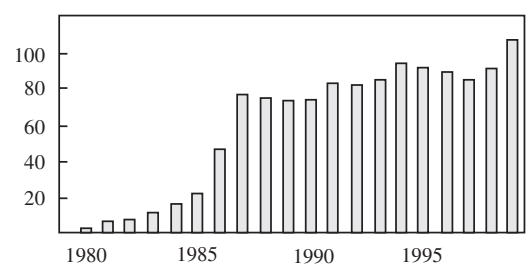

As a percent of GNP

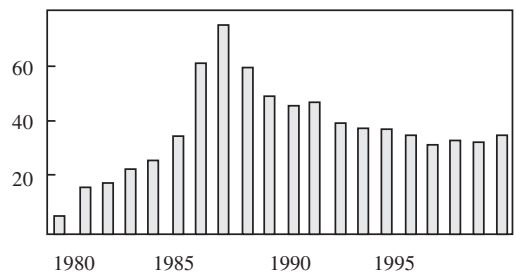

Weeks of import cover

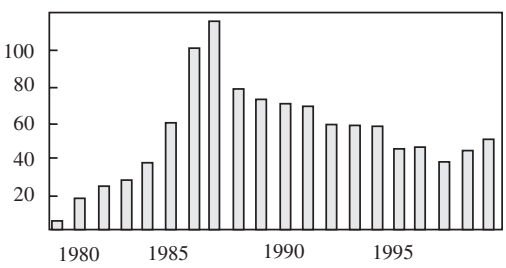

Reserves/M2

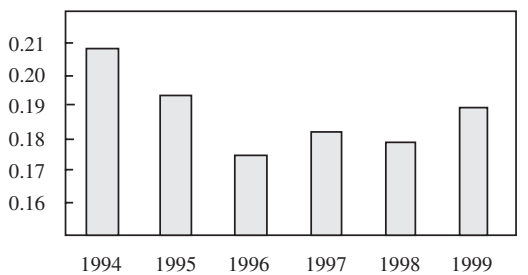

Sources: Central Bank of China; Directorate-General of Budget, Accounting and Statistics; Republic of China, "Monthly Statistics of the Republic of China."

\section{South Korea}

South Korea's international reserve holdings plummeted during the 1997-98 Asian financial crisis but have since grown dramatically. From a low of $\$ 6$ billion in usable international reserves at end-1997, reserves rose 766 percent over the next year, to $\$ 52$ billion. Usable reserves rose a phenomenal 1,500 percent over the 1998-2000 period, to $\$ 96.2$ billion by the end of 2000 . The leading European credit rating agency (Fitch IBCA) called this remarkable turnaround in international reserves "unprecedented in modern rating history." ${ }^{3}$ Korea held five times more total reserves at the end of 2000 than it did at the beginning of the 1990s.

The increase in Korea's reserves started in earnest in 1988, with liberalization of capital transactions, capital inflows and intervention in the foreign-exchange market by the monetary authorities to prevent serious appreciation of the won. Between 1987 and 1988, reserves almost quadrupled. They also increased sharply between 1993 and 1995. When Thailand abandoned its fixed exchange rate in the summer of 1997, Korea's reserve position seemed

3. Times (London), December 23, 1998, "Fitch Puts South Korea on Review," www.thetimes.co.uk/section/0,158,00.html). 
strong. Its end-of-June 1997 reserve holdings were put at $\$ 33$ billion. However the central bank had placed foreign-currency deposits with foreign branches of domestic Korean banks. While this practice had actually begun in the late 1980s, the amounts had stayed small (less than 10 percent of total reserves) until 1997. During 1997 the share of reserves placed with these foreign branches increased. Because of liquidity pressures facing the banks, these offshore deposits of international reserves could not be withdrawn when Korea faced a crisis that October. Market turbulence was exacerbated by the realization that the international reserves the central bank could use in a crisis were considerably less than its reported official reserves. Though Korea's official reserve holdings at the end of December 1997 were \$20 billion, its usable reserves were only $\$ 6$ billion.

The swing in Korea's current-account balance from deficit to surplus in 1998 amounted to 15 percent of GDP, far outweighing Mexico's experience during its 1994-95 crisis. Usable international reserves rebounded, reflecting the move to current-account surplus, and, as investor confidence returned, inflows from foreign investors. Korea's stock market rebounded in mid-1998 and closed that year as the best performing emerging market. Although the won is still below its pre-crisis level, concerns about the effects of its appreciation on export competitiveness mounted in early 1999. The central bank has intervened to limit the appreciation, increasing its reserve holdings. The central bank also attributes the increase in its reserve holdings in 2000 to repayments by domestic financial institutions of their foreign-exchange loans borrowed from the central bank. ${ }^{4}$

Private analysts frequently comment that the experience of 1997 strongly influenced the Korean monetary authorities. For example, one firm reported: "The authorities still seemed anxious to prioritize the acquisition of foreign exchange over other more orthodox policy concerns." ${ }^{5}$ Korea's central bank reserves now account for almost 20 percent of GNP, compared with about 7 percent in 1996 and at the start of the 1990s. Reserves now represent about thirty weeks of import cover, up from 11.8 weeks in 1996, and 12.9 weeks at the start of the 1990s. Today Korea has the second-highest level of international reserves within the Organization for Economic Cooperation and Development (after Japan) and the fifth-largest holdings in the world (after Japan, China, Hong Kong, and Taiwan).

4. Korea Economic Weekly, various issues.

5. World of Information Country Report, February 1, 2001, p. 25. 
Figure A-2. South Korea's Reserve Holdings

Total reserves (billions of dollars)

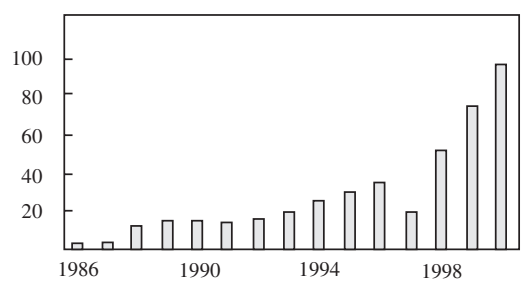

As a percent of GNP

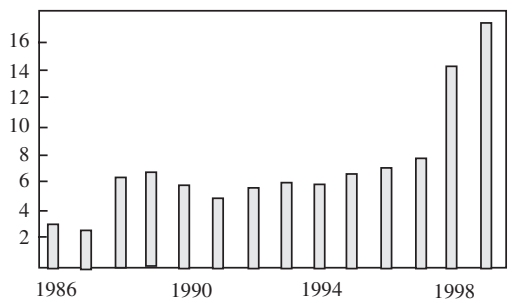

Weeks of import cover

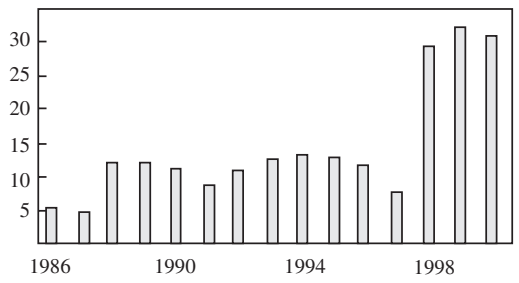

Reserves/M2

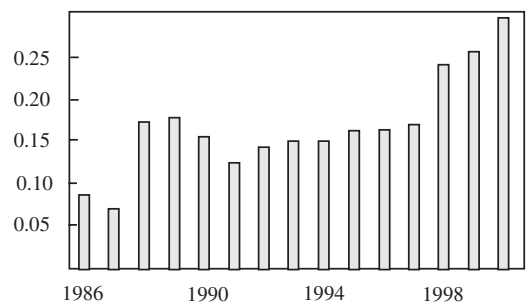

Source: Authors' calculations using data from the IMF's International Financial Statistics. Details can be found in appendix B.

\section{China}

In the second half of the1990s, China's current-account surpluses and relatively strong foreign direct investment (FDI) inflows allowed it to increase its international reserve holdings. During the 1980s reserves averaged about 4.5 percent of GNP. In the second half of the 1990s, reserves averaged a much larger 14 percent of GNP.

China had $\$ 158$ billion in reserves at the end of 1999 , which represented 16 percent of its GNP, fifty weeks of import cover, 10 percent of M2, and about four times its short-term foreign-currency debt. By the end of January 2001 , reserves had exceeded $\$ 170$ billion.

The domestic currency is convertible only on current account; strict controls apply to all capital transactions. In 1995 and 1996 China's current-account surplus was 0.2 percent of GNP and 0.9 percent of GNP, respectively. In 1997 the surplus rose to 3.2 percent; it was 2.5 percent in 1998 , and 1.5 percent in 1999. In response to these surpluses, as well as to the FDI inflows, the authorities have tried to keep the currency stable, allowing only a very modest appreciation since 1994. China chose not to devalue during the Asian crisis, 
Figure A-3. China's Reserve Holdings

Total reserves (billions of dollars)

Weeks of import cover
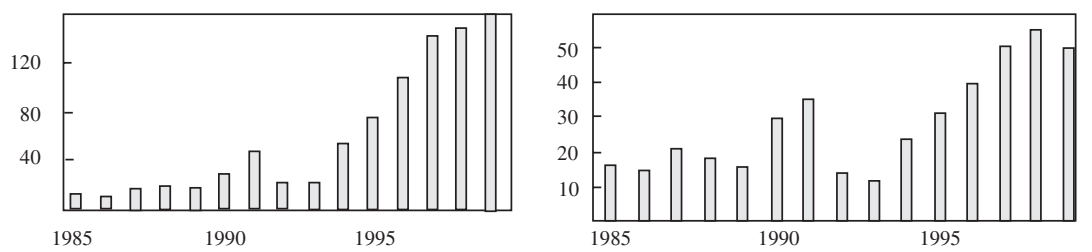

As a percent of GNP

Reserves/M2
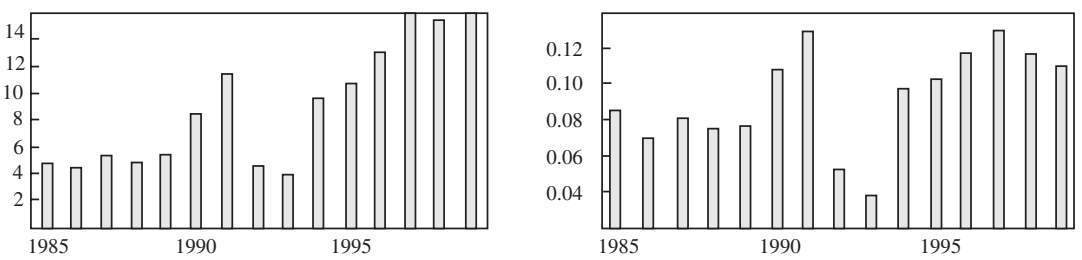

Source: Authors' calculations using data from the IMF's International Financial Statistics. Details can be found in appendix B.

and it has continued to keep its currency fixed since early 1995 at 8.3 renminbi to the U.S. dollar.

China did not face financial turmoil during the 1997-98 Asian financial crisis because it had capital controls. Witnessing the damage inflicted on the financial and corporate sectors of its neighbors, it took measures to tighten its already strict foreign debt management. At the end of 1997, its foreign debt was U.S.\$134 billion, about 80 percent of it long term and about half of it borrowed from international organizations and foreign governments. Its capacity to service foreign debt, as measured by the growth of its international reserves, has kept pace with the growth of foreign liabilities. Consequently, the key debt ratios have been kept well within the generally accepted safety limits. ${ }^{6}$ In particular, total foreign debt is well under 20 percent of GDP, the debt service ratio is under 11 percent and international reserves are four times larger than short-term debt.

In the late 1990s analysts began commenting on the relative stability of Chinese reserve holdings in light of its ongoing current-account surpluses and relatively strong inflows of FDI. Some have concluded that money is being held offshore. ${ }^{7}$ In particular, the stability in reserve holdings may be due to 
the leakage of foreign capital outflows and to the hoarding of foreign exchange earnings by exporters. ${ }^{8}$

China favors having sizable reserve holdings. It believes that international reserves help it maintain the foreign confidence needed for attracting foreign direct investment and securing foreign loans at good terms. ${ }^{9}$

\section{APPENDIX B}

All series listed in this appendix are obtained from the IMF's International Financial Statistics and are used for authors' calculations throughout this article.

\section{Variable}

Reserves exclud ing gold

Gold

Reserves including gold

Real reserves

Period average exchange rate

Nominal effective exchange rate

Interest rates

\section{Definition}

Series '.1LDZF', quoted in dollars. Global reserves excluding gold is global reserves including gold, Series '001.1..DZF' minus global gold holdings, Series '001.1AD.ZF' (gold in ounces), multiplied by 35 (gold in SDRs), then valued in dollars using the dollar/SDR exchange rate, Series '111..AA.ZF'.

Series '.1AD.ZF' (Gold in ounces), multiplied by 35 (gold in SDR), and then valued in dollars using the end-of-period dollar/SDR exchange rate (Series '111..AA.ZF').

Sum of reserves excluding gold and gold. Global reserves including gold is series ' 001.1..DZF'.

Reserves are deflated with U.S. GNP deflator (series '111..99BIR', extended backwards using older publications, 1975=100).

Series '..RF.ZF', quoted in national currency per dollar.

Monthly data for trade-weighted nominal exchange rate based on period average exchange rate, weights obtained from IMF. The rate is expressed as an index $(1957: 1=100)$, with an increase indicating an appreciation. This series was used to construct the annual measures of exchange-rate volatility.

For the FJ replication, the government bond yield in series ' 61 ...ZF' was used for most countries. The discount rate in series '60...ZF' was used for Austria, Sweden, Japan, Finland, Greece, and Iceland. For the later regressions, the choice of interest rate used was based on maximum availability. The money market rate in series '60B..ZF' was used for Belgium, Brazil, Denmark, India, Korea, Malaysia, Netherlands,

8. Barclay's Bank, Country Report, August 1998.

9. Ford and Huang (1994). 
South Africa, Spain, Thailand, Japan, and Pakistan. The deposit rate in series '60L..ZF' was used for Argentina, Chile, Colombia, Costa Rica, Indonesia, Jamaica, and Venezuela. The Treasury Bill rate in series '60C..ZF' was used for Mexico, Philippines, and Sweden. The lending rate in series '60P..ZF' was used for Finland and Israel. The government bond yield in series ' 61 ...ZF' was used for Australia, Austria, Canada, Germany, France, Ireland, Italy, New Zealand, Norway, Portugal, Switzerland, and the United Kingdom. The interest rate differential was constructed as $\ln ((1+i) /(1+$ is $))$, where is is the U.S. interest rate corresponding to the definition used for the national interest rate.

GNP

Imports

Exports

Monetary base

M1

Quasi-money

M2
Series '99A.ZF' or '99AC.ZF' (gross national income) for most countries. For Japan, Switzerland, Hong Kong, Egypt, Nicaragua, Peru, the United Kingdom, Portugal, Tunisia, Mexico, and South Africa, series '99B..ZF' or '99BC.ZF' (GDP) was used. For Turkey, the GDP series '186..99B..ZF' was extended backwards using the real GDP volume index '186..99BVPZF' (1995=100), inflated with the CPI '186..64.XZF', linking the two series in 1995. All measures are quoted in national currency, and converted into U.S. dollars using the period average exchange rate. Global GDP is from IMF's World Economic Outlook, Series 'W001NGDPD'.

Series '71.DZF' (Imports, c.i.f., quoted in U.S. dollars). For Belgium, series '12498C..ZF' (imports of goods and services) was used, converted into dollars using the period average exchange rate. Global import weeks is Series '0171.DZF' divided by 52 .

Series '70.DZF' (exports, quoted in dollars).

Series ' $14 \ldots$ ZF', quoted in national currency. For Austria, Belgium, Finland, France, Germany, Ireland, Italy, Netherlands, Portugal, and Spain the sum of series '14A..ZF' (currency in circulation) and '14C..ZF' (liabilities to banking institutions in the country) was used. For the United Kingdom, series '11259MC.ZF' (M0) was used.

Series '34...ZF', quoted in national currency. For Austria, Belgium, Finland, France, Germany, Ireland, Italy, Netherlands, and Portugal the sum of '34A..NZF' (currency in circulation) and '34B..NZF' (demand deposits) was used. For Spain the series '18459MA.ZF' (M1) was used. For Sweden the series '144..39M.ZF' (broad money) was used.

Series '35...ZF', quoted in national currency. For Austria, Belgium, Finland, France, Germany, Ireland, Italy, Netherlands, Portugal, and Spain the series '35..NZF' was used.

The sum of M1 and quasi-money. For Sweden and the United Kingdom the series '35L..ZF' (money plus quasi-money) was used. For 
France and Germany the series '39MBCZF' (M2, seasonally adjusted) was used. For the Netherlands the series '39.CZF' (M2, seasonally adjusted) was used. The M2 series are quoted in national currency and were converted into dollars using the period average exchange rate.

Shadow-rate fun- First domestic credit $\mathrm{D}$ was constructed by subtracting reserves damental F including gold (expressed in national currency using the period average exchange rate) from the monetary base. This difference was then multiplied by (100/U.S. CPI), where the U.S. CPI is represented in the series '111..64..ZF'. The monthly series is used to construct annual measures for the volatility of the shadow-rate fundamental.

Capital inflows Sum of absolute values of series '78BEDZF', '78BGDZF', and '78BIDZF' (quoted in dollars).

Capital outflows Sum of absolute value of series '78BDDZF', '78BFDZF', '78BHDZF', and '78CADZF' (quoted in dollars).

Real openness Sum of absolute value of imports and absolute value of exports.

Financial open- Sum of capital inflows and capital outflows ness

\section{Bias from Skewness}

The potential upward bias in the estimated coefficient on volatility arises from the interaction between reserve volatility and measurement error in reserves, the dependent variable. To see the nature of the possible bias, consider the following example. Suppose that reserves follow a random walk with drift:

$$
R_{t}=\mu+R_{t-1}+v_{t},
$$

where $\mu$ is the constant drift and $v$ a zero-mean disturbance with nonconstant variance. Between discrete adjustments, reserves follow the Wiener process described earlier. But when $R_{t-1}$ is at its lower limit, the value of $v$ is special. It is large and positive, because it is the inventory restocking under the Frenkel and Jovanovic (FJ) null. We therefore discard the assumption that $v$ is distributed normally and instead let it be skewed positively.

To compute reserve volatility for our example, we use a one-year rolling variance of reserves rather than the fifteen-year rolling standard deviation used 
by FJ. Thus our volatility measure is simply the square of the once-lagged reserves disturbance,

$$
\sigma_{t}^{2}=v_{t-1}^{2}
$$

Our FJ-style reserve estimating equation is: ${ }^{1}$

$$
R_{t}=\beta_{0}+\beta_{1} \sigma_{t}^{2}+\varepsilon_{t} .
$$

In $(\mathrm{C}-2)$ the $\beta_{i}$ are regression coefficients and $\varepsilon_{t}$ is a regression disturbance assumed to be uncorrelated with the volatility measure.

If $\mathrm{FJ}$ are correct in their assumption that all reserve observations are very close to the optimal value, $R_{0}$, then we know from the definition of a least squares estimator that

$$
\hat{\beta}_{1}=\operatorname{cov}\left(R_{0}, \sigma_{t}^{2}\right) / \operatorname{var}\left(\sigma_{t}^{2}\right) .
$$

We can then use our estimated value for $\hat{\beta}_{1}$ to test the theory against the alternative that $\beta_{1}=0$.

But suppose, realistically, there is measurement error in our reserves variable. Observed reserves are off a bit from their optimal value. Perhaps two periods ago they were at their optimal level, $R_{t-2}=R_{0}$, but given the random walk process in $(\mathrm{C}-1)$, last period they were at $R_{t-1}=R_{0}+\mu+v_{t-1}$ and this period they are at $R_{t}=R_{0}+2 \mu+v_{t-1}+v_{t}$. Now our estimated coefficient will be

$$
\hat{\beta}_{1}=\operatorname{cov}\left(R_{t}, \sigma_{t}^{2}\right) / \operatorname{var}\left(\sigma_{t}^{2}\right)
$$

where

$$
\operatorname{cov}\left(R_{t}, \sigma_{t}^{2}\right)=\operatorname{cov}\left(R_{0}, \sigma_{t}^{2}\right)+E\left(v^{3}\right) .
$$

Since $v$ is skewed positively by large reserve adjustments, $E v^{3}>0$ simply as a statistical artifact of restocking. An investigator, therefore, would find $\beta_{1}>$ 0 regardless of optimal inventory behavior in the presence of uncertainty. ${ }^{2}$

1. For clarity in the example, we have suppressed the opportunity cost effect and made the estimating equation linear in levels using a variance measure rather than a standard deviation.

2. Regression biases induced by skewness are confronted frequently in the finance literature since researchers often attempt to explain asset returns, in part, by the variability of those returns. See, for example, Shin and Stulz (2000). 


\section{Shadow Exchange Rate and International Reserves Model}

A warning is appropriate here. Our reinterpretation of the reserve inventory model and its empirical implementation requires us to rely on a macroeconomic model of exchange-rate determination-hardly the most robust building block in the economist's toolkit. ${ }^{3}$ This is the price economists pay for choosing to work with volatility measures that involve endogenous variables. We must rely on some sort of first stage model that then generates the final volatility measure.

The macro model we use in the text and in our empirical work to specify shadow exchange-rate behavior is the monetary model of the shadow rate introduced by Flood and Garber and estimated by Blanco and Garber. ${ }^{4}$ The model consists of the following equations:

$$
\begin{gathered}
\frac{M}{P}=\beta-\alpha i+\varepsilon, \\
P=P^{*} S \delta, \\
i=i^{*}+\frac{\dot{S}}{S} .
\end{gathered}
$$

In (C-3) M is the high-powered money supply; $P$ is the domestic price level; $i$ is the domestic-currency interest rate, and $\varepsilon$ is a money-demand error term that captures all factors influencing real money demand other than the interest rate. In (C-4) $P^{*}$ is the foreign price level; $S$ is the exchange rate quoted as the domestic-currency price of foreign exchange and $\delta$ is the real exchange rate. Equation C-5 imposes uncovered interest parity. The domestic interest rate equals the foreign rate $i^{*}$ plus the expected (actual) rate of change of the nominal exchange rate. This model is well known and we use it here as a starting point for that reason.

The model brings in international reserves through the asset backing of high power money, $M \equiv R+D$, where $R$ is the domestic-currency book value of international reserves and $D$ is domestic credit. Rearranging equation C-3, we see that while the exchange rate is controlled, reserves follow:

$$
R_{t}=P_{t}^{*} \vec{S} \delta_{t}\left(\beta-\alpha i_{t}+\varepsilon_{t}\right)-D_{t} .
$$

3. See, for example, Flood and Rose (1995).

4. Flood and Garber (1984). Blanco and Garber (1986). 
The shadow exchange rate equilibrates the money market in equation C-3 under the condition that reserves have been driven to their constant lower boundary (assumed here to be zero) and the exchange rate is allowed to float freely in the sense that the reserve authority does not intervene in the foreignexchange market.

We now substitute (C-4) and (C-5) into (C-3), substitute D for the money base since reserves have been driven to their zero lower bound, and solve for the shadow exchange rate, $\tilde{S}$. We find that the shadow exchange rate at time $\mathrm{t}$ is equal to:

$$
\tilde{S}_{t}=F_{t}+\lambda \dot{\tilde{S}}_{t}
$$

where the fundamentals driving the shadow exchange rate are

$$
F_{t}=\left(D_{t} / P_{t}^{*}\right) / \gamma_{t} \text {, }
$$

with

$$
\gamma_{t} \equiv \delta\left[\beta-\alpha i^{*}+\varepsilon_{t}\right], \lambda=\delta \alpha / \bar{\gamma} \text {, and } \bar{\gamma}
$$

representing the long-term average value of $\gamma_{t}{ }^{5}$

A complete solution for the shadow exchange rate described by equation C-7 requires information about the time-series process of fundamentals. We assume that fundamentals follow a random walk with drift,

$$
F_{t}=F_{t-1}+\mu+v_{t},
$$

where $\mu$ is the drift parameter and $v$ is a white noise disturbance. ${ }^{6}$ When fundamentals follow equation $\mathrm{C}-8$, the shadow exchange rate, in turn, must follow:

$$
\tilde{S}_{t}=F_{t}+\lambda \mu \text {. }
$$

5. Our shadow rate fundamental is $D /\left(P^{*} \gamma\right)$ in theory. In our empirical implementation, $\gamma$ is held constant at $\bar{\gamma}$. This is a potentially important simplification that is exactly consistent with Flood and Garber (1984), but removes all real volatility from our new volatility measure. Expunging real volatility contrasts with early studies that captured primarily real-side volatility. In the 1960s and 1970s, extensive capital controls meant that volatility in external payments represented primarily volatility in trade flows. Indeed, some early empirical studies focused solely on volatility in export earnings.

6. We assume that $v$ is distributed normally, so

$$
v_{t} \sim\left(0, \sigma_{v}^{2}\right) \text {. }
$$

There is no skewness problem. If there are big jumps in fundamentals, or if these jumps are correlated with reserve jumps, as might be the case if the reserve authority follows a policy of sterilized intervention in the foreign-exchange market, then skewness problems will arise and again contaminate the estimation of reserve holdings. We address this issue in our paper. 
Its rate of change is equal to the growth rate of fundamentals.

If our replacement for the variance of reserve increments is to match FJ exactly, then increments to the right-hand-side of (C-6) must have the same variance as increments to the shadow-rate fundamental defined in (C-8). This is true exactly (for small increments and a very short-term interest rate) in a log linear shadow rate model (as in Flood and Marion (2000)), but can hold here only as an approximation since we are working with a level-linear exchange rate model.

Our ability to substitute fundamentals volatility for reserve volatility is assured once we recognize that the expected value of reserves conditional on their not having hit the lower boundary since they were reset at $R_{0}$ is just the conditioning information we need to exclude both upward restocking reserve jumps and downward successful speculative attacks. Consequently, the expected value of reserves depends only on its initial optimal value and the distribution of the fundamentals that drive the shadow rate until it hits its upper bound. From (C-8) the increments to the fundamentals are distributed normally, just as FJ had hoped their reserve increments would be. ${ }^{7}$

\section{Coskewness}

When we estimated the reserve-holding equation using the reserves volatility measure, we tested for skewness. When the fundamentals volatility measure is used instead, the appropriate analog is coskewness. If $v$ is the reserve increment and $\varepsilon$ is the fundamentals increment, then skewness is $E v^{3}$ and coskewness is $E v \varepsilon^{2}$. We were unable to find a simple coskewness statistic analagous to Pearson's SK statistic, so we made up our own break-point measure based on

$$
\rho=\operatorname{Cov}\left(v, \varepsilon^{2}\right) /\left(\operatorname{Var}(v) * \operatorname{Var}\left(\varepsilon^{2}\right)\right)
$$

for $v, \varepsilon$ as above.

7. In our empirical implementation, we try two different replacements for reserve volatility. When $\bar{S}$ is piecewise stable (for example, moving with time-to-time devaluations) we use the volatility of shadow-rate fundamentals. This is the option we report in the text. Our method is not appropriate, however, when $\bar{S}$ is moving stochastically but nearly continuously (for example, when $\bar{S}$ is stabilized partially or smoothed). In the latter situation, the relevant volatility measure is the volatility of fundamentals that influence $\tilde{S}-\bar{S}$. 


\section{Comments and Discussion}

Pierre-Richard Agénor: Flow measures of the "adequacy" of official reserves continue to permeate policy discussions and applied research on macroeconomic management. In an attempt to determine the extent of quasi-fiscal losses associated with sterilization in Chile during the 1990s, for instance, Gallego, Hernández, and Schmidt-Hebbel calculated the cost resulting from the large and rapid accumulation of international reserves at the central bank (from $\$ 2.5$ billion in 1988 to $\$ 17.8$ billion in 1997). ${ }^{1}$ They did so by estimating the stock of "excess" reserves held (defined as the difference between the actual and "optimal" level of reserves) and multiplying it by the difference in returns on domestic debt (that is, the interest rate paid on central bank instruments) and that of foreign assets. Under one scenario, they estimated the "optimal" level of reserves by using the average ratio between reserves and monthly imports over the period 1985-88, which gave a value of 6.9 months of imports.

By contrast most of the recent theoretical developments (and some empirical studies as well) on the determinants of currency crises have emphasized the "stock" approach to the adequacy of reserves, in particular the role that short-term external debt (relative to reserves) may have on the likelihood of a currency crisis. ${ }^{2}$ A key reason for this, of course, is related to the higher degree of capital mobility witnessed during the past decade and the increased vulnerability of pegged exchange rate regimes to speculative attacks. In addition available data indicate that holdings of official reserves have increased in recent years, even in countries that have adopted flexible exchange rate regimes. In this context, revisiting the issue of what determines holdings of official

1. Gallego, Hernández, and Schmidt-Hebbel (1999).

2. See, for example, Chang and Velasco (2000). 
reserves, as Robert Flood and Nancy Marion (FM) are doing in their paper, cannot be more timely.

The first part of FM's paper provides a useful descriptive analysis of the evolution of official reserves during the period 1960-99 and I have little to add to it —except to point out that, when looking at developing countries, some disaggregation might be useful. Table 1 shows that official reserves as a ratio of imports of goods and services have increased during the 1990s for developing countries as a whole. This is consistent with the data compiled by FM in their table 1. In addition the data in my table indicate that the increase in the reserves-imports ratio was particularly marked for fuel-exporting countries. For nonfuel, primary product exporting countries, official reserves fell slightly between 1993 and 2000. Interestingly enough fuel-exporting countries are those countries which most of the evidence pertaining to asymmetric access to world capital markets refers to (see below).

I will start this paper by presenting a general specification of the demand for international reserves that summarizes fairly well the type of regression models used in the early or "conventional" literature. I will then review the implications of a high degree of capital mobility for the demand for reserves. In addition, this paper provides a slightly more detailed presentation of the Frenkel-Jovanovic continuous time inventory control framework, on which FM draw, and summarizes the FM contribution and raises a variety of issues regarding their analytical and empirical results.

Most studies of the demand for international reserves typically assume that reserves are held to meet international payments and for precautionary reasons. A specification form that summarizes many of the determinants that have been emphasized in the early literature is

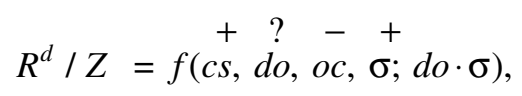

where

$R^{d}$ : demand for reserves (often measured in gross terms)

$Z$ : a scale factor

cs: country size

$d o$ : the degree of openness of the country, often measured by the propensity to import

$o c$ : a measure of the opportunity cost of holding reserves

$\sigma:$ a measure of the variability of payments and receipts.

In conventional empirical studies, these variables are defined as follows: 


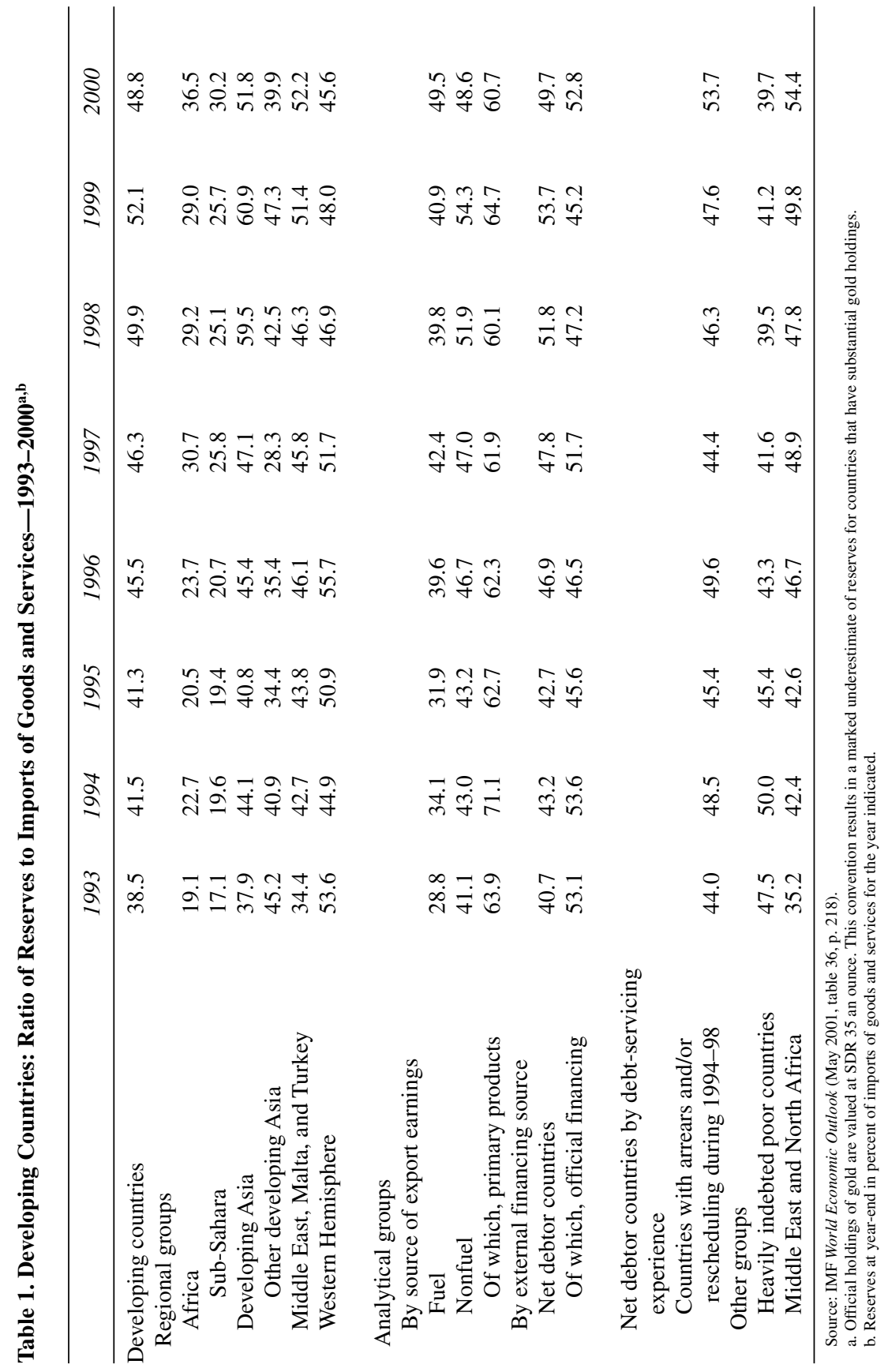


- The scale factor, $Z$, is either domestic income or imports. In several studies, reserves are not scaled (in which case $Z=1$ ) or are measured in real terms (in which case $Z$ is the level of domestic prices).

- Country size, $c s$, is often measured by income per capita; it is assumed to have a positive effect.

- The degree of openness, $d o$, is often measured by the propensity to import. It has in general an ambiguous effect on the demand for reserves. Heller, for instance, argued that in the hypothetical case in which a country runs out of reserves, any temporary deficit in the balance of payments would have to be corrected by means of a reduction in aggregate expenditure; the required adjustment is smaller the higher the propensity to import. ${ }^{3}$ This implies a negative relationship between reserves and the propensity to import. On the contrary, Frenkel argued that the propensity to import reflects the economy's openness and thus measures its vulnerability to external shocks. ${ }^{4}$ In this case the demand for reserves should be positively related to the import propensity.

- The opportunity cost of holding reserves, $o c$, is often measured as an interest rate on domestic-currency denominated assets, or more appropriately for the case of reserves that are mostly held in interest-bearing assets abroad, the difference in interest rates between domestic and foreign-currency denominated assets. It is expected to have a negative effect.

- The variability indicator, $\sigma$, is assumed to have a positive effect: The higher the variability of external payments, the higher the level of reserves a country wants to hold. Variability has often been measured in empirical studies by the standard deviation (or coefficient of variation) of either actual or residual movements in reserves. ${ }^{5}$ Some authors have also used the variability of export receipts or the variability of the terms of trade. ${ }^{6}$ The justification for these measures is that volatility in external payments and receipts was dominated essentially by fluctuations in trade flows in the 1960s and 1970s and that continues to be the case for small Caribbean countries and many sub-Saharan African countries.

I have also added in equation (1) the interactive term, $d o \cdot \sigma$, to capture an often neglected point in empirical studies - the fact that the more open the

3. Heller (1966).

4. Frenkel (1978).

5. For instance, Saidi (1981) used the variability of a permanent component. He argued that movements in current variability are expected to change the desired level of reserves only if they imply a change in the perceived permanent level of variability. In the absence of full current information as to the source of a change in variability, only a fraction of the current change in variability will be attributed to a change in the permanent component.

6. Kelly (1970) and Iyoha (1976); Williams, Polius, and Hazel (2001). 
economy, the more vulnerable the country is to "real" volatility (for example, terms-of-trade shocks), and the more important the precautionary motive is likely to be. I will return to this issue below.

Simplifying somewhat, the conventional empirical literature (which in some cases assumed partial adjustment of actual reserves to their desired value given in equation (1)) found that country size, the degree of openness, and volatility tend to have a positive effect on the demand for reserves. By contrast, the effect of the opportunity cost has been difficult to identify with precision.

As noted by FM, the increase in the degree of capital mobility in the 1990s has been accompanied by two related developments: i) an increased frequency in the occurrence of currency and financial crises, and ii) a tendency to shift to flexible exchange rates. In principle, under such a regime, there is no need for a country to hold international reserves because payments imbalances are corrected (eventually) by movements in its exchange rate. However, there are at least three reasons for continuing to hold reserves under flexible exchange rates:

- The exchange rate may be managed because of the desire by the monetary authorities to avoid unexpectedly large movements in the domestic currency. The reason is that increased exchange rate variability can make international transactions riskier and more expensive by either increasing the cost of forward transactions at all maturities, or reducing the availability of forward cover over longer maturities. Moreover, if the shift to a flexible exchange rate is accompanied by an increase in the degree of capital mobility, destabilizing capital flows may result in an increase of reserves when moving from fixed to flexible exchange rates.

- Reserves can be used as collateral for borrowing on world capital markets and are an indicator of the probability of default on loan. Relatively low reserves may act as a signal of a higher probability of default on international loans and consequently lead to higher borrowing costs, as measured for instance by interest rate spreads on world capital markets.

- The expectation of an eventual return to fixed rates may lead to an accumulation of reserves - both to defend the currency under future speculative attacks and as a precaution if future shocks are expected.

The first two considerations have important implications for the estimation of the demand for reserves. The first implies that one must account for the degree of flexibility of the exchange rate desired by the monetary authorities, and the fact that movements in the exchange rate may depend on official 
reserves as a result of "smoothing" operations. The second implies that interest rate spreads on world capital markets may depend on the country's stock of official reserves. This makes econometric estimates such as those of Edwards, who uses the difference between the interest rate faced by developing countries in the Eurocurrency market and LIBOR as a measure of the opportunity cost of reserves, highly suspect. ${ }^{7}$ I will return to the first implication below.

The point of departure of Flood and Marion's paper is the buffer stock model of reserve holdings developed by Frenkel and Jovanovic (FJ), which essentially argues that the optimal level of reserves must be chosen so as to balance the adjustment costs incurred in the absence of reserves with the opportunity cost of holding these reserves. ${ }^{8}$

FM summarize very well the structure of the FJ model and its implications, but for the benefit of the reader let me provide a slightly more complete derivation of its key result. FJ's model is based on the principles of inventory management and begins by assuming that changes in reserve holdings, $d R(t)$, evolve according to the following stochastic specification:

$$
d R(t)=-\mu d t+\sigma d W(t), \quad R(0)=R^{*},
$$

where $W(t)$ is a Wiener process (that is, the continuous time analogue to a random walk), a process with increments $d W(t)$ that are statistically independent and normally distributed with mean zero and variance equal to the increment in time, $d t$. $W(t)$ itself also has mean zero and variance $t . \mu \geq 0$ is the deterministic part of the instantaneous change in reserves. $R^{*}$ denotes the optimal stock of reserves, which is assumed to be held initially. Equation (2) indicates that the change in reserves in a small interval of time $d t$ is a normal variate with mean $-\mu d t$ (a negative drift) and variance $\sigma^{2} d t$, and is temporally independent. At any point in time, the distribution of reserve holdings is thus characterized by

$$
R(t)=R^{*}-\mu t+\sigma W(t),
$$

and $R(t) \sim N\left(R^{*}-\mu t ; \sigma^{2} t\right)$. The case $\mu=0$ implies no drift in the process driving changes in reserves.

FJ determine the optimal stock of reserves by considering two components of cost: the cost of adjustment (for example, the decline in real income needed to achieve a current account surplus) incurred when reserves reach a lower

7. Edwards (1985).

8. Frenkel and Jovanovic (1981). 
bound (zero for simplicity), and forgone earnings on the existing stock of reserves. These two components are, of course, related: a higher stock of reserves reduces the chance of having to adjust and thereby reduces the expected cost of adjustment; but this additional "precaution" is obtained at the cost of higher forgone earnings. The optimal stock $R^{*}$ is determined by minimizing the sum of the expected values of both components of cost.

The first component of total costs, expected forgone earnings (up to the date at which the first adjustment is necessary), is given by

$$
J_{1}\left(R^{*}\right)=r \int_{0}^{\infty} e^{-r t}\left[\int_{0}^{\infty} R h\left(R, t \mid R^{*}, 0\right) d R\right] d t,
$$

where $r$ is the opportunity cost (in percent) of holding reserves per unit of time, and $h\left(R, t \mid R^{*}, 0\right)$ is the probability that reserve holdings, which at period 0 are at the optimal level $R^{*}$, have not reached zero prior to period $t$. Following the derivations in the appendix to Frenkel and Jovanovic, this expression can be shown to be equal to

$$
J_{1}\left(R^{*}\right)=R^{*}-(1-\alpha)(\mu / r),
$$

where

$$
\alpha=\exp \left\{\left(-R^{*} / \sigma^{2}\right)\left[\left(\mu^{2}+2 r \sigma^{2}\right)^{1 / 2}-\mu\right]\right\}{ }^{9}
$$

The present value of the expected cost incurred following the first adjustment is given by

$$
J_{2}\left(R^{*}\right)=\int_{0}^{\infty} e^{-r t}\left[C+G\left(R^{*}\right)\right] f\left(R^{*}, t\right) d t,
$$

where $C$ is a fixed adjustment cost and $G\left(R^{*}\right)$ is the present value of total cost (excluding $C$ ) and $f\left(R^{*}, t\right)$ the probability that reserve holdings reach zero for the first time at $t$. The above expression can be re-written as

$$
J_{2}\left(R^{*}\right)=\alpha\left[C+G\left(R^{*}\right)\right],
$$

Adding equation (5) and equation (7) and rearranging yields the present value of total expected cost:

$$
G\left(R^{*}\right)=\left(R^{*}+\alpha C\right) /(1-\alpha)-\mu / r .
$$


Minimizing this expression with respect to $R^{*}$ and expanding the optimality condition in Taylor series around $R^{*}$ and ignoring terms of third and higher order, yields

$$
R^{*}=\left\{\left(2 C \sigma^{2}\right) /\left[\left(\mu^{2}+2 r \sigma^{2}\right)^{1 / 2}-\mu\right]\right\}^{1 / 2},
$$

that is, in the case with no drift $(\mu=0)$ :

$$
R^{*}=\left\{\left(2 C \sigma^{2}\right) /\left(2 r \sigma^{2}\right)^{1 / 2}\right\}^{1 / 2}=A \sigma^{1 / 2} r^{-1 / 4},
$$

where $A$ is a constant term that depends on the fixed adjustment $\operatorname{cost} C$. Equations (9) and (10) are the fundamental results of the FJ model. They indicate that the optimal level of reserves varies positively with the volatility of reserves and negatively with the opportunity cost of holding reserves.

In their empirical analysis, which focuses on industrial countries and covers the 1960s and early 1970s, FJ compute $\sigma$ for each year as the standard deviation over the previous fifteen years of the trend-adjusted annual changes in the actual stock of reserves. The opportunity cost of holding reserves is proxied by either the government bond yield or the discount rate.

There are several problems with the Frenkel and Jovanovic model, both analytical and empirical. As pointed out by Jung, for instance, the model can lead to unrealistic predictions, because it incorporates no upper bound of reserve management as a control variable. ${ }^{10}$ If reserves hit their lower bound, then the central bank adjusts it to an optimal level; but as long as reserves are above the lower bound, the central bank does nothing. As a result, since the stochastic process is such that reserves can increase to infinity, all reserves cannot be lent out in order to earn interest. In such a case, one cannot minimize total expected cost. ${ }^{11}$ Most importantly for our purpose here, is the definition of the volatility measure in the empirical part of the paper. Why fifteen years, as opposed to five or twenty-five? FJ are silent on this issue. In a revealing exercise, FM replicate the estimation of FJ's model, using their measure of volatility and varying the window used to construct it. They show that FJ's measure lacks robustness because it is only when the window is extended that the coefficient of that variable becomes positive.

After reviewing FJ's contribution, FM make the following fundamental argument: FJ's measure of volatility is inadequate, because it does not separate typical changes in volatility (the Wiener increments) from the potentially

10. Jung (1995).

11. Jung (1995) showed that with both upper and lower bounds on reserves, the optimal stock is adjusted more frequently, compared to the FJ case. 
large upward adjustments in reserves that occur as a result of optimal restocking behavior. Actual data on reserves mix together reserve changes induced by optimal management by the central bank and changes that result from private-sector behavior. Including the big upward adjustments induced by private sector behavior imparts positive skewness to the reserve increments measure and leads to a potential upward bias in the estimated coefficient on volatility. Moreover, this become particularly important in a context of high capital mobility and recurrent crises, because large reserve increments may be as likely to be generated by speculative attacks (big downward shocks) as by occasional restocking of reserve inventories.

Flood and Marion argue that, therefore, there are two problems:

- Currency crises generate large negative reserve increments before reserves hit their lower bound, violating the assumption that reserves follow a Wiener process up until they hit their lower bound. Crises impart negative skewness to the reserve increment measure.

- Calculating reserve volatility by relying on multi-period rolling averages will capture the large positive reserve increments that characterize reserve restocking. Including the restocking increments imparts positive skewness to the reserve increment measure.

Because the two types of big reserve shocks do not generally cancel out, the reserve increment process is a mixture of typical increments (possibly distributed normally) plus some sort of endogenous jump process. Downward jumps are associated with speculative attacks whereas upward jumps are related to changes in macroeconomic policy that induce reserve accumulation.

FM then propose a new measure of volatility that relies on what I may call an "equivalence proposition": the probability of reserves hitting their lower bound is identical to the probability of the "shadow" exchange rate hitting the pegged rate from below. Using the standard Krugman-Flood-Garber model of currency crises, they derive an expression of the shadow rate in terms of fundamentals. They go on to replace FJ's measure of reserve volatility with a measure of volatility based on the behavior of fundamentals (essentially real domestic credit), which are assumed to follow a random walk with drift.

This equivalence proposition is, in my view, the key contribution of FM's paper. The paper offers a number of additional contributions, which I summarize briefly as follows:

- They use market-determined interest rates to construct a measure of the opportunity cost of holding reserves in developing countries. 
- They measure reserves as a proportion of a stock variable, in addition to flow variables, in some of their empirical regressions, in line with the recent literature on currency crises.

- They account for the degree of exchange rate flexibility, by using a measure of the volatility of the actual nominal effective exchange rate, with the prior expectation that a higher degree of flexibility leads to less reserve holdings. Again, I will return to this issue below.

They estimate their model using panel data for a group of twenty developed countries and sixteen developing countries (including Korea and Mexico) over the period 1988-97. SigF, the volatility of the shadow-rate fundamentals (essentially domestic credit), is measured as the standard deviation of the previous two years of monthly shocks to the fundamentals process. Their results show that the variable is robust and does not depend on window size. They conclude that reserve holdings remain strongly influenced by volatility and opportunity costs. The conclusion regarding the latter variable is somewhat overstated, given that the opportunity cost variable is not reliably negative and significant in FM's results.

I agree with most of Flood and Marion's analysis and conclusions, but would suggest the following ideas to consider:

-The "equivalence proposition" is a general statement, which is logically distinct from any particular model driving the fundamentals that influence the shadow rate. Any practical implementation, of course, must make a specific "choice" of a model; any "error" in specifying or selecting this model may invalidate the analysis. This "omitted variables problem" may be severe if one considers the list of possible "fundamentals" that the new theories of currency crises might suggest — ratio of short-term debt to reserves, unemployment, and so on. Put differently, the relatively low explanatory power of the basic regressions of the demand for reserves may result from the fact that the monetary model chosen by FM to derive the process of fundamentals may be incomplete or, at worst, wrong. Indeed, the empirical results improve significantly when the variables controlling for the degree of real and financial openness are introduced in the regressions. But this is an ad hoc treatment; these variables could be proxying for a host of factors, which are not clearly identified in the analytical framework that FM use.

-FM's results indicate that their measure of the volatility of the actual nominal exchange rate, sigS, is not robustly associated with the demand for reserves. One possible reason is that they may face an endogeneity problem, which is related to the fact that (as I indicated earlier) the degree of exchange 
rate flexibility is influenced by the process driving reserves, as a result of "smoothing" considerations; if intervention is successful, one would expect volatility to be small. In theory, what accounting for this would require is the specification of the model driving the exchange rate itself-a task that may well go beyond FM's objective in this paper.

In addition to these direct comments on the specification and estimation of FM's model, I have a more fundamental point. I would argue that, at least for developing countries, focusing exclusively on financial volatility as FM do, is debatable. This is, in a sense, going to the other extreme, compared to the literature focusing only on trade-related volatility. The key problem for developing countries in deciding how much reserves to hold, I would argue, is their higher exposure to "bad" shocks (both real and financial, both domestic and external) and their limited ability to smooth the impact of these shocks on their balance of payments through world capital markets. As FM themselves note, there is an asymmetry between developed countries (who can borrow when they need it) and developing countries, whose access to world capital markets tends to be pro-cyclical. ${ }^{12}$ One would therefore expect that, for developing countries, terms-of-trade shocks for instance would have an asymmetric effect on reserves. Indeed, a high incidence of "bad" (external) shocks may affect the precautionary demand for reserves: lack of access to international capital markets in bad times may necessitate accumulating higher levels of reserves in "good" times, compared to what is deemed optimal when shocks are treated symmetrically and access to world capital markets is counter-cyclical. If this argument is correct, it implies that pooling industrial and developing countries (as done by FM and many others in the literature) is not a good idea. It also suggests that focusing on a measure of volatility that is purely "financial" may not be appropriate: re-introducing "real" volatility (in the form, say, of volatility of the terms of trade, interacted with the degree of openness) may be important.

Despite these limitations, I believe that Flood and Marion have provided an important contribution to the re-thinking of the role of reserves in a world of high capital mobility. They may not have provided all the answers to the questions that they have raised, but without a doubt their analysis will provide food for further thought for many international economists. 
Barry Eichengreen: Robert Flood and Nancy Marion have written the best paper providing the most serious analysis of the demand for international reserves that I have had the pleasure of reading in recent years. Before you conclude that I am going overboard in my flattery of the authors, I should add that theirs is also virtually the only paper with any serious analysis of the demand for international reserves that has appeared in recent years. I used the EconLit data base to tabulate the number of articles in which the phrase "international reserves" appeared in the title, the results of which are in figure $1 .{ }^{1} \mathrm{I}$ conjecture that we could explain much of the variation in this time series with a Frenkel dummy and an Edwards dummy. A more structural explanation would point to a first flurry of interest in this topic in the 1970s, prompted by the belief that contemporary international monetary problems reflected the extent to which reserves had been in short supply (and then by the creation of excess reserves through the issuance of special drawing rights (SDRs) at precisely the wrong time), and to a second flurry of interest associated with the question of how the shift to floating exchange rates affected the demand for reserves. But the point to which I want to draw attention is that the intellectual resources devoted to this topic have fallen off dramatically in recent years.

This is a peculiar state of affairs. Governments continue to devote large amounts of public-sector resources to the accumulation of reserves. It is hard to argue that this is just an anachronistic hangover from prior history, since countries have not just held onto their inherited reserves but in a number of cases built them up still further. Moreover reserves are not a particularly remunerative investment. The Greenspan-Guidotti rule is that countries should accumulate a cushion of reserves equal to all foreign obligations falling due within twelve months. ${ }^{2}$ Since they may pay twice or more to borrow abroad what they earn on those reserve holdings, this strikes many of us as peculiar advice, especially if it is not accompanied by the further recommendation that they should also take steps to limit the volume of short-term borrowing. And if sterilized intervention is not very effective, then it is not clear that these assets are very useful for stabilizing the exchange rate. So there is a mystery to be solved.

Why has it not received more attention? I would point to two factors, both of which are familiar to the authors. First, we lack an adequate theoretical

1. I have been unable to determine whether coverage of 2000 is complete. In constructing figure 1 I eliminated duplicates and entries that were reprints of articles that originally appeared outside the sample period. One could, of course, also search for "international reserves" by subject, but would then be at the mercy of the judgments of those who classify these articles.

2. See Guidotti (1999) and Greenspan (1999). 
Figure 1. Articles on International Reserves per Year, 1965-2000

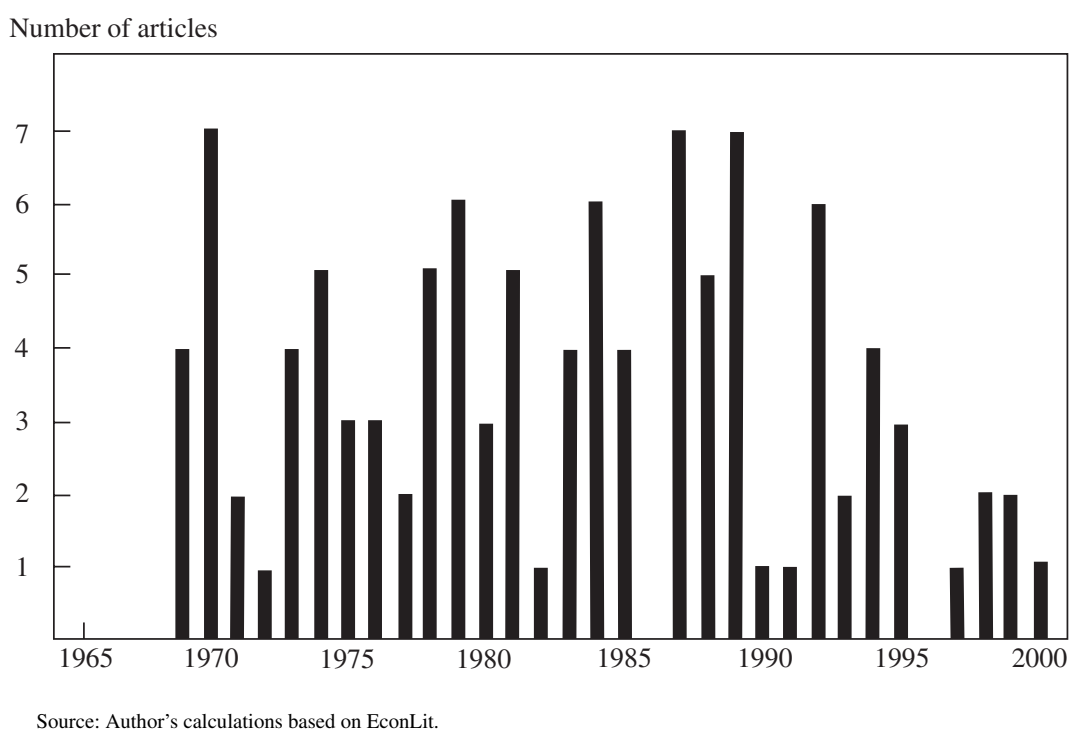

framework on which to base empirical analyses of the demand for reserves. Many governments presumably hold reserves as protection against crises, or, more precisely, in order to avoid having to take the difficult policy adjustments needed in short order if speculative pressures are to be fended off. Unfortunately the framework commonly used in most empirical studies of the demand for reserves predates the literature on speculative attacks. And a framework that does not accommodate such attacks will have a hard time accounting for the demand for reserves.

Second, there is the problem of measuring actual reserve holdings. Are we talking about gross or net reserves? How do we value derivatives and contingent assets and liabilities? Is \$35 an ounce the right price at which to value gold? How do we distinguish official from usable reserves? (Recall how in 1997 Korea deposited many of its reserves with the offshore branches of its banks, rendering them unavailable for conventional uses.)

The authors have the courage to confront these obstacles because they have an insight into how to adapt the buffer-stock model of international reserves to a world of high capital mobility. In the buffer-stock model, built for an age when capital mobility could be ignored, reserves declined smoothly when the current account was in deficit, until they reached a floor (typically but not nec- 
essarily zero) where the authorities felt compelled to undertake the policy adjustments needed to rebuild them. Thus one simply had to model the determinants of that smooth decline or, more minimally still, the stochastic process characterizing it. But in a world with capital mobility, reserves can decline abruptly if the currency is attacked. ${ }^{3}$ Flood and Marion draw on the literature on speculative attacks, using the fundamentals driving the shadow exchange rate and therefore the likelihood of a crisis, to proxy for this event. This enables them to adapt the buffer stock model to a world of capital mobility.

But this solution creates a problem of its own. Attempts to implement this approach will only be as good as one's model of exchange rate determination, as the authors themselves put it. In the present context I prefer to put the point differently: implementation will only be as good as one's empirical model of speculative attacks. ${ }^{4}$ We know from the literature on leading indicators that empirical models of currency crises perform poorly. ${ }^{5}$ Theory suggests that currency crises are heterogeneous. They may be caused by the slow deterioration of macroeconomic fundamentals (as in first generation models) or result from self-fulfilling attacks. To be sure, theoretical models have pointed to the kind of variables that can sap a government's ability to defend itself and thereby render it vulnerable to attack, but the domestic considerations that governments weigh when contemplating a costly defense of the currency vary across time and country. High unemployment, weak economic growth, a fragile banking system, and large amounts of short-term debt may have rendered governments reluctant to hike interest rates in the past, but one could imagine in the future that a government will be concerned instead with the level of property prices, the solvency of a heavily indebted nonfinancial corporation, or some very different consideration.

A close look at attempts to build early-warning systems underscores these points. These studies show that the estimated relationship between observable macroeconomic and financial indicators and the probability of large changes in exchange rates and reserves tends to be very sensitive to the sample of countries and the period for which the exercise is carried out. This belies the notion

3. The authors and their collaborators have shown this in a long line of theoretical papers.

4. The distinction is essentially semantic, since empirical models of currency crises perform poorly for all the same reasons that empirical models of exchange rate determination perform poorly. If a speculative attack occurs when the exchange rate is out of equilibrium, in other words, then a model of speculative attacks will have to be able to characterize that equilibrium value in order to say when it does not obtain. And for more than fifteen years we have been aware that we lack an adequate model of equilibrium exchange rate determination.

5. This is the theme of Rose and Svensson (1994), Berg and Pattillo (1999), and Eichengreen and Rose (1999). 
that there exists a single set of variables and a stable set of relationships on which crisis forecasting can be based. Since most attacks come as surprises, models which rely on time-series data almost always predict "no crisis."

In particular the fundamental in the simple Flood-Garber model, the rate of domestic credit growth, is a very poor predictor of attacks. Blanco and Garber found that this variable could explain the timing of speculative attacks on the Mexican peso up through the early 1980s fairly well, but it has poor explanatory and predictive power elsewhere. ${ }^{7}$

This fact presents our authors with a dilemma. On the one hand, while acknowledging that we lack an adequate model of the determinants of the shadow exchange rate and therefore the risk of a speculative attack, they can claim that all they are aspiring to do is to illustrate the method. They can then draw on the simple if not very realistic model of Flood and Garber as an illustration of how to move from theory to empirics while warning us not to take their particular estimates too seriously. On the other hand, they can make a serious attempt to model the determinants of the shadow exchange rate by including as explanatory variables the host of factors pointed to in the literature on leading indicators of currency crises. If they pursue this option they are entitled to claim that their particular estimates should be taken seriously, but the reader is equally entitled to question their results. And so long as we lack adequate models of exchange-rate and crisis determination, there is no way out of this bind.

Parenthetically I have always been slightly uncomfortable with the buffer stock framework. While the model alludes to the opportunity cost of holding reserves and to the cost of adjusting them, to a large extent these underlying determinants are simply loaded into the past variability of reserves. In principle, we can measure the opportunity cost of holding reserves and include it in the model. But the relevant rate-of-return variables are hard to construct. The authors use the domestic interest rate relative to the foreign interest rate

6. Indeed suppose that forecasts of a country's vulnerability trigger corrective policy actions which then prevent a crisis. In this case the model would appear to forecast poorly, since the potential for a crisis would never be followed by an actual crisis.

7. Blanco and Garber (1986). That this variable should have worked for Mexico prior to the mid-1980s but not subsequently is no surprise. Mexico's crises prior to the time Blanco and Garber wrote were heavily driven by macroeconomic imbalances. In a world of tightly regulated financial systems and limited capital mobility, there was less scope for the political and financial fragilities that have figured so prominently in subsequent models. This is precisely why subsequent scholars have been led to construct second, third, and $n$th generation models of currency crises, in which a variety of other variables influence and in turn are influenced by the probability of an attack. 
as a measure of opportunity cost. These would appear to be own-currency interest rates, unadjusted for inflation differentials and expected changes in the exchange rate, which does not strike me as analytically appropriate. (A footnote suggests that adjusting these for actual exchange rate changes fails to improve the fit.) I am skeptical that even an analytically appropriate opportunity cost measure would work very well, since most of the relevant assets are short term and covered interest differentials are very small at short horizons. The authors append exchange rate variability to the model to proxy for country-specific variations in the cost of adjustment, but this clearly is no more than a first stab at the problem. I suspect that this may be why countryspecific fixed effects play such a large role in the empirical analysis.

Why else could these fixed effects be important? They could be picking up country-specific variations in taste. Taiwan and South Korea place a higher value on reserves than other countries because they worry more about large armies just beyond their borders and shores. Or they could be picking up measurable economic characteristics that influence the demand for reserves. The earlier literature-much of which predates the buffer-stock model on which the authors focus - suggests that more heavily indebted economies hold more reserves. Countries with more variable terms of trade hold more reserves. Conceivably, some of these variables could be included as additional shadow fundamentals. Or they could be added as additional shift variables, in the manner that the authors add the volatility of the actual exchange rate as such a shifter. This would come at some sacrifice of analytical purity, but it seems to be what the data are calling for.

In conclusion, I congratulate the authors for opening - or, more accurately, reopening - an important research topic. They have made a significant contribution by showing how analytical models of the demand for reserves can be adapted to a world of high capital mobility. But as for whether they and their followers can successfully move from theory to empirics, I have my doubts.

General discussion: Dani Rodrik emphasized that holding excessive levels of foreign exchange reserves has very high opportunity costs for developing countries. In his own recent work, he has calculated the costs for countries such as Korea and Peru, which have very large reserve stocks, and compared them to the costs of poverty programs in these countries and elsewhere. For example, he finds that Peru's spending on excess reserves is two to three times 
the cost of a poverty program—such as the relatively successful program in Mexico.

Rodrik believes that these types of calculations highlight the importance of better understanding why many countries hold such high reserve levels and of assessing the costs and benefits of doing so. However, he questioned whether testing the inventory (or buffer-stock) model of reserve holdings is the best way to address these issues and suggested that much may be learned from other tactics that are not wedded to this approach.

Susan Collins was struck by the number of countries in which reserve holdings followed the "shark-tooth" pattern predicted by the inventory model. But these sometimes recurring episodes typically lasted for no more than a few years. This suggested to her that it would be interesting to study the regime shifts, when these sub-periods end, to gain more insight into which country factors and global factors would be important in specifying a broader framework for studying reserve holdings.

Nancy Marion responded that she believes the appropriate way to study reserve holdings is with a systematic approach, one that begins by exploring what can be learned from the buffer stock model used in this paper. She argued that there remains considerable scope for extending this approach. For instance, more work needs to be done to improve measures of volatility and opportunity cost. 


\section{References}

Barclays Bank PLC Economics Department. 1998. Barclays Bank Country Report: China. (August).

Baumol, William J. 1952. "The Transactions Demand for Cash: An Inventory Theoretic Approach.” Quarterly Journal of Economics 66 (November): 545-56.

Ben-Bassat, Avraham, and Daniel Gottlieb. 1992. "Optimal International Reserves and Sovereign Risk.” Journal of International Economics 33 (November): 345-62.

Berg, Andrew, and Catherine Pattillo. 1999. "Are Currency Crises Predictable? A Test." International Monetary Fund Staff Paper 46 (June).

Blanco, Herminio, and Peter M. Garber. 1986. "Recurrent Devaluation and Speculative Attacks on the Mexican Peso." Journal of Political Economy 94 (February): 148-66.

Bussière, Matthieu, and Christian Mulder. 1999. "External Vulnerability in Emerging Market Economies: How High Liquidity Can Offset Weak Fundamentals and the Effects of Contagion.” Working Paper 99/88. International Monetary Fund, Policy Development and Review Department (July).

Calvo, Guillermo A.. 1996. "Capital Flows and Macroeconomic Management: Tequila Lessons." International Journal of Finance and Economics 1 (July): 207-23.

Calvo, Guillermo A., and Carmen M. Reinhart. 2000. "Fear of Floating." Working Paper 7993. Cambridge, Mass.: National Bureau of Economic Research (November).

Chang, Roberto, and Andrés Velasco. 2000. "Banks, Debt Maturity, and Financial Crises." Journal of International Economics 51 (June): 169-94.

Claassen, Emil-Marie. 1975. "Demand for International Reserves and the Optimum Mix and Speed of Adjustment Policies." American Economic Review 65 (June): 446-53.

Dadush, Uri, Dasgupta Dipak, and Dilip Ratha. 2000. "The Role of Short-Term Debt in Recent Crises." Finance and Development 37 (December): 54-57.

Disyatat, Piti, and Donald Mathieson. 2001. "Currency Crises and the Demand for Foreign Reserves.” Mimeo (April). Washington: International Monetary Fund, Research Department.

Edwards, Sebastian. 1983. "The Demand for International Reserves and Exchange Rate Adjustments: The Case of LDCs, 1964-72.” Economica 50 (August): 269-80.

- 1985. "On the Interest-Rate Elasticity of the Demand for International Reserves: Some Evidence from Developing Countries." Journal of International Money and Finance 4 (June): 287-95.

Eichengreen, Barry, and Andrew Rose. 2000. "The Empirics of Currency and Banking Crises." Wirtschafts Politische Blätter 47 (4): 395-402 (haas.berkeley. edu/ arose/NBERRep.pfd). 
Fischer, Stanley. 2001. "Distinguished Lecture on Economics in GovernmentExchange Rate Regimes: Is the Bipolar View Correct?" Journal of Economic Perspectives 15 (2): 3-24.

Flood, Robert P., and Peter M. Garber. 1984. "Collapsing Exchange-Rate Regimes: Some Linear Examples.” Journal of International Economics 17 (August): 1-13.

Flood, Robert P., and Olivier Jeanne. 2000. "An Interest Rate Defense of a Fixed Exchange Rate?" Working Paper 00/159. Washington: International Monetary Fund (October).

Flood, Robert P., and Nancy Marion. 1999. "Perspectives on the Recent Currency Crisis Literature." International Journal of Finance and Economics 4 (1): 1-26.

2000. "A Model of the Joint Distribution of Banking and Exchange-Rate Crises." Working Paper 01-03, Dartmouth College (December).

Flood, Robert, and Andrew Rose. 1995. "Fixing Exchange Rates: A Virtual Quest for Fundamentals." Journal of Monetary Economics 36 (December): 3-37.

Ford, J. L., and Guobo Huang. 1994. "The Demand for International Reserves in China: An ECM Model with Domestic Monetary Disequilibrium.” Economica 61 (August): 379-97.

Frenkel, Jacob A. 1974. "The Demand for International Reserves by Developed and Less-Developed Countries." Economica 41 (February): 14-24.

1978. "International Reserves: Pegged Exchange Rates and Managed Float." In Economic Policies in Open Economies, edited by Karl Brunner and Allan H. Meltzer. Amsterdam: Carnegie-Rochester Conference Series on Public Policy Vol. 9.

. 1980. "The Demand for International Reserves under Pegged and Flexible Exchange Rate Regimes and Aspects of the Economics of Managed Float." In The Functioning of Floating Exchange Rates: Theory, Evidence, and Policy Implications, edited by David Bigman and Teizo Taya, 169-95. Cambridge, Mass.: Ballinger Publishing Company.

1983. "International Liquidity and Monetary Control.” In International Money and Credit: The Policy Roles, edited by George M. von Furstenberg, 65-109. Washington: International Monetary Fund.

Frenkel, Jacob A., and Boyan Jovanovic. 1980. "On Transactions and Precautionary Demand for Money.” Quarterly Journal of Economics 95 (August): 25-43.

_. 1981. "Optimal International Reserves: A Stochastic Framework." Economic Journal 91 (June): 507-14.

Gallego, Francisco, Leonardo Hernández, and Klaus Schmidt-Hebbel. 1999. "Capital Controls in Chile: Effective? Efficient?" Working Paper 59. Central Bank of Chile (December).

Greenspan, Alan. 1999. "Currency Reserves and Debt: Remarks by Chairman of the Board of Governors of the Federal Reserve System before the World Bank Conference on Recent Trends in Reserves Management." Washington. (29 April) (www.federalreserve.gov/boarddocs/speeches/1999/19990429.htm). 
Grubel, Herbert G.. 1971. "The Demand for International Reserves: A Critical Review of the Literature." Journal of Economic Literature 9 (December): 1148-66.

Guidotti, Pablo E. 1999. Remarks to the G-33 Seminar, Bonn, Germany (March 11).

Hamada, Koichi, and Kazuo Ueda. 1977. "Random Walks and the Theory of Optimal International Reserves.” Economic Journal 87 (December): 722-42.

Hausmann, Ricardo, Ugo Panizza, and Ernesto Stein. 2000. "Why Do Countries Float the Way They Float?" Working Paper 418. Washington: Research Department, InterAmerican Development Bank (May).

Heller, Heinz Robert. 1966. “Optimal International Reserves.” Economic Journal 76 (June): 296-311.

International Monetary Fund. 2001. "World Economic Outlook May 2001: Fiscal Policy and Macroeconomic Stability." Washington: International Monetary Fund.

Iyoha, Milton A. 1976. "Demand for International Reserves in Less Developed Countries: A Distributed Lag Specification." Review of Economics and Statistics 58 (August): 351-55.

Jung, Chulho. 1995. "Optimal Management of International Reserves." Journal of Macroeconomics 17 (Fall): 601-21.

Kelly, Michael G. 1970. "The Demand for International Reserves." American Economic Review 60 (September): 655-67.

Kenen, Peter B., and Elinor B. Yudin. 1965. "The Demand for International Reserves." Review of Economics and Statistics 47 (August): 242-50.

Krugman, Paul. 1979. "A Model of Balance-of-Payments Crises." Journal of Money, Credit, and Banking 11 (August): 311-25.

Kuo, Shirley W.Y., and Christina Y. Liu. 1998. "Taiwan.” In East Asia in Crisis: From Being a Miracle to Needing One? edited by Ross H. McLeod and Ross Garnaut, 179-88. Routledge Press.

Lizondo, José Saúl, and Donald J. Mathieson. 1987. "The Stability of the Demand for International Reserves." Journal of International Money and Finance 6 (September): $251-82$.

Miller, Merton H., and Daniel Orr. 1966. "A Model of the Demand for Money by Firms." Quarterly Journal of Economics 80 (August): 413-35.

Radelet, Steven, and Jeffrey D. Sachs. 1998. "The East Asian Financial Crisis: Diagnosis, Remedies, Prospects." Brookings Papers on Economic Activity 1: 1-74.

Rose, Andrew K., and Lars E. O. Svensson. 1994. "European Exchange Rate Credibility before the Fall.” European Economic Review 38 (June): 1185-216.

Saidi, Nasser. 1981. "The Square-Root Law, Uncertainty, and International Reserves under Alternative Regimes: Canadian Experience, 1950-1976." Journal of Monetary Economics 7 (May): 271-90.

Salant, Stephen W., and Dale W. Henderson. 1978. "Market Anticipations of Government Policies and the Price of Gold." Journal of Political Economy 86 (August): 627-48. 
Shin, Hyun-Han, and René M. Stulz. 2000. "Shareholder Wealth and Firm Risk." Working Paper 2000-19. Charles A. Dice Center for Research in Financial Economics. Ohio State University (December).

Tobin, James. 1956. “The Interest Elasticity of Transactions Demand for Cash.” Review of Economics and Statistics 38 (August): 241-47.

Williams, Oral, Tracy Polius, and Selvon Hazel. 2001. "Reserve Pooling in the Eastern Caribbean Currency Union and the CFA Franc Zone: A Comparative Analysis." International Monetary Fund.

World of Information. 2001. Country Report: South Korea. Essex: Walden Publishing. 